\title{
Screening novel genes by a comprehensive strategy to construct multiple stress-tolerant industrial Saccharomyces cerevisiae with prominent bioethanol production
}

\author{
Li Wang $^{1,4}$, Bo Li $i^{1,4}$, Ran-Ran Su ${ }^{2,3}$, Shi-Peng Wang ${ }^{1,4}$, Zi-Yuan Xia ${ }^{1,4}$, Cai-Yun Xie ${ }^{1,3,4^{*}}$ and Yue-Qin Tang ${ }^{1,2,3,4^{*}}$ (0)
}

\begin{abstract}
Background: Strong multiple stress-tolerance is a desirable characteristic for Saccharomyces cerevisiae when different feedstocks are used for economical industrial ethanol production. Random mutagenesis or genome shuffling has been applied for improving multiple stress-tolerance, however, these techniques are generally time-consuming and labor cost-intensive and their molecular mechanisms are unclear. Genetic engineering, as an efficient technology, is poorly applied to construct multiple stress-tolerant industrial S. cerevisiae due to lack of clear genetic targets. Therefore, constructing multiple stress-tolerant industrial $S$. cerevisiae is challenging. In this study, some target genes were mined by comparative transcriptomics analysis and applied for the construction of multiple stress-tolerant industrial S. cerevisiae strains with prominent bioethanol production.

Results: Twenty-eight shared differentially expressed genes (DEGs) were identified by comparative analysis of the transcriptomes of a multiple stress-tolerant strain E-158 and its original strain KF-7 under five stress conditions (high ethanol, high temperature, high glucose, high salt, etc.). Six of the shared DEGs which may have strong relationship with multiple stresses, including functional genes (ASP3, ENA5), genes of unknown function (YOL162W, YORO12W), and transcription factors (Crz1 p, Tos8p), were selected by a comprehensive strategy from multiple aspects. Through genetic editing based on the CRISPR/Case9 technology, it was demonstrated that expression regulation of each of these six DEGs improved the multiple stress-tolerance and ethanol production of strain KF-7. In particular, the overexpression of ENA5 significantly enhanced the multiple stress-tolerance of not only KF-7 but also E-158. The resulting engineered strain, E-158-ENA5, achieved higher accumulation of ethanol. The ethanol concentrations were 101.67\% and $27.31 \%$ higher than those of the E-158 when YPD media and industrial feedstocks (straw, molasses, cassava) were fermented, respectively, under stress conditions.
\end{abstract}

Conclusion: Six genes that could be used as the gene targets to improve multiple stress-tolerance and ethanol production capacities of $S$. cerevisiae were identified for the first time. Compared to the other five DEGs, ENA5 has a more vital function in regulating the multiple stress-tolerance of $S$. cerevisiae. These findings provide novel insights into the efficient construction of multiple stress-tolerant industrial S. cerevisiae suitable for the fermentation of different raw materials.

\footnotetext{
*Correspondence: xiecy@scu.edu.cn; tangyq@scu.edu.cn

${ }^{1}$ College of Architecture and Environment, Sichuan University, No. 24

South Section 1 First Ring Road, Chengdu 610065, Sichuan, China

Full list of author information is available at the end of the article
}

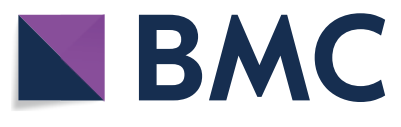

(c) The Author(s) 2022. Open Access This article is licensed under a Creative Commons Attribution 4.0 International License, which permits use, sharing, adaptation, distribution and reproduction in any medium or format, as long as you give appropriate credit to the original author(s) and the source, provide a link to the Creative Commons licence, and indicate if changes were made. The images or other third party material in this article are included in the article's Creative Commons licence, unless indicated otherwise in a credit line to the material. If material is not included in the article's Creative Commons licence and your intended use is not permitted by statutory regulation or exceeds the permitted use, you will need to obtain permission directly from the copyright holder. To view a copy of this licence, visit http://creativecommons.org/licenses/by/4.0/. The Creative Commons Public Domain Dedication waiver (http://creativeco mmons.org/publicdomain/zero/1.0/) applies to the data made available in this article, unless otherwise stated in a credit line to the data. 


\section{Highlights \\ Novel genes related to stress tolerance were mined by a comprehensive strategy. \\ Stress tolerance was improved by regulating expression of each of the novel genes. \\ Overexpression of ENA5 enhanced ethanol production under all stress conditions. \\ Ethanol titer of the engineered strain increased by $41.35 \%$ at high temperature. \\ Ethanol titer of the engineered strain increased by $121.42 \%$ at salt stress condition}

Keywords: Saccharomyces cerevisiae, Multiple stress-tolerance, Comparative transcriptome, ENA5, ASP3, Crz1p

\section{Graphical Abstract}

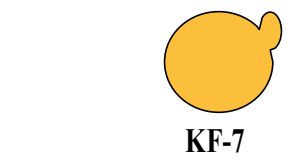

Mutagenesis

and hybridization

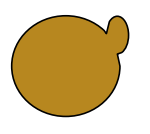

E-158

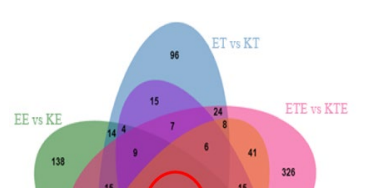

Transcriptome under five stress conditions

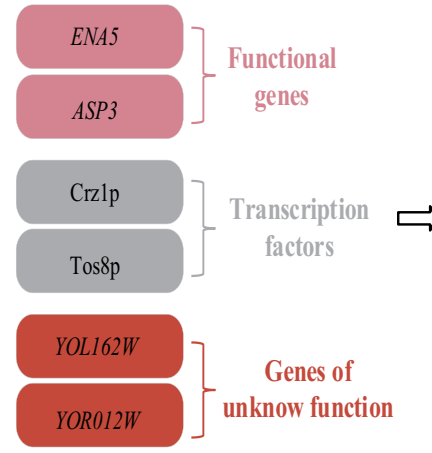

Expression regulation

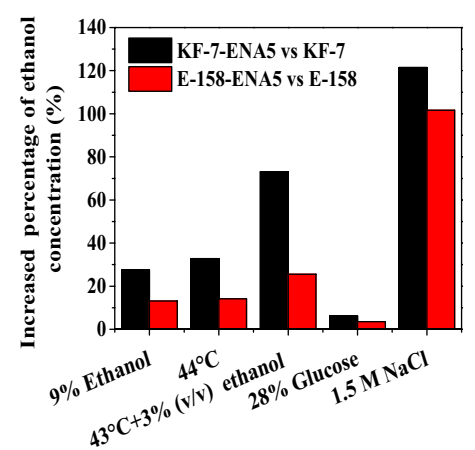

Fermentation

\section{Background}

Bioethanol, an eco-friendly renewable biofuel, is one of the alternatives of fossil gasoline [1]. Bioethanol production is based on the fermentation of starchy (cassava, corn, microalgae, etc.), sugary (molasses, sweet sorghum/ sugarcane juice, etc.), or lignocellulosic (straw, corn cob, etc.) biomass [1, 2]. Species including Saccharomyces cerevisiae, Kluyveromyces marxianus, Zymomonas mobilis, and Pichia stipites are bioethanol producers [3-5]. S. cerevisiae is the main species used for industrial ethanol production due to its good fermentation performance and stress resistance [6-8]. However, S. cerevisiae is commonly exposed to different kinds of environmental stresses in the industrial fermentation process with different feedstocks. For example, in simultaneous saccharification and fermentation (SSF) with lignocellulosic or starchy biomass as feedstock, S. cerevisiae is expected to resist high temperatures (since the optimal enzymatic saccharification temperature is $45-50{ }^{\circ} \mathrm{C}$ ) and high ethanol concentration [9-11]. Similarly, during very high gravity (VHG) fermentation using sugar-based raw materials (molasses, concentrated sweet sorghum juice, and sugarcane juice), strains should withstand the high concentration of sugar at the early stage and high ethanol concentration at the later stage [12]. Moreover, molasses without acid pretreatment has high salt content, which notably impedes the fermentation efficiency of S. cerevisiae [13, 14]. Such environmental stresses possibly cause lipid peroxidation, protein denaturation, DNA damage, cell apoptosis, etc., of S. cerevisiae [15, 16]. Extensive improvements of the multiple stress-tolerance and robustness of S. cerevisiae are of paramount to achieve high bioethanol production.

However, breeding multiple stress-tolerant industrial S. cerevisiae strains that perform well when using whichever feedstocks is still challenging [17]. Presently, some studies have reported that stress-tolerance of strains can be improved by random mutagenesis [18], genome shuffling [19], and genetic engineering [17]. Compared with random mutagenesis and genome shuffling, genetic engineering is of great significance because of short breeding time, clear gene targeting and clear relationship between gene and phenotype. Over the past decades, studies have reported that a number of genes were closely related to ethanol, heat, or osmosis stress tolerance of $S$. cerevisiae $[9,20-22]$, which can be used as the potential targets to improve stress tolerance of the strains. Based on these findings, a number of trials have been performed. For example, overexpression of ISU1 and JAC1 increased the ethanol tolerance [23] and overexpression of HSF1 and MSN2 promoted cell growth and high temperature fermentation [24]. Salt tolerance can be enhanced by over expressing CDS1 and CHO1 [25]. However, these studies mainly focused on the improvement of resistance to 
single stress (high ethanol or high temperature). To our knowledge, none of the genes linking to multiple stresstolerance has been reported to date. Since $S$. cerevisiae strains are forced to face diverse environmental stresses during the industrial fermentation, it is vital to identify gene targets that could be engineered to improve multiple stress-tolerance of $S$. cerevisiae.

In our previous study, a S. cerevisiae strain E-158 was obtained by random mutagenesis and hybridization, which shows higher capability of multiple stress-tolerance than its original strain KF-7 [18]. To identify potential target genes related to multiple stress-tolerance, in the present study, the comparative transcriptome analysis was performed between strain E-158 and its original strain KF-7 under five stress conditions. Six target genes which possibly contribute to the multiple stress-tolerant phenotypes of $S$. cerevisiae were mined by a comprehensive strategy. CRISPR/Cas9 technology was used to regulate the expression of these six target genes to explore their impacts on the multiple stress-tolerance phenotypes of S. cerevisiae. Moreover, the stress tolerance of the engineered strains was assessed using three kinds of typical industrial feedstocks.

\section{Results}

\section{Fermentation performance of original strain KF-7} and resistant strain $\mathrm{E}-158$

In our previous study, an excellent multiple stress-tolerant strain E-158 was obtained by using a strategy of random mutagenesis and hybridization [18]. The strain E-158 showed higher ethanol production and glucose consumption rates than the original strain KF-7 under five stress conditions. The final concentrations of ethanol produced by E-158 during batch fermentations were $66.89 \%, 33.37 \%, 81.02 \%, 10.14 \%$, and $35.98 \%$, respectively, higher than those of KF-7 under five stress conditions: (1) $8.0 \%$ (v/v) initial ethanol, (2) $44{ }^{\circ} \mathrm{C}$, (3) $43{ }^{\circ} \mathrm{C}$ and $2.6 \%$ (v/v) initial ethanol, (4) $27 \%$ glucose, (5) $1.25 \mathrm{M} \mathrm{NaCl}$ (Fig. 1).

\section{Comprehensive strategy of mining key genes regulating stress-tolerant phenotypes of S. cerevisiae}

To mine the potential key genes governing the multiple stress-tolerant phenotypes of S. cerevisiae, transcriptional profiles of strains KF-7 and E-158 under five stress conditions were investigated based on RNA-seq with three biological replicates (the RNA extraction times were shown in Fig. 1, and the gene expression levels of KF-7 under same stress conditions were taken as the control group). According to differential expression analysis of RNA-seq data, hundreds of DEGs were found under each kind of stress condition (Fig. 2A).

Twenty-eight DEGs were found shared under all five stress conditions via Venn diagram (Fig. 2B, Additional file 1: Table S1), suggesting their potential contributions to multiple stress-tolerant phenotypes. GO and KEGG analyses revealed that these DEGs were involved in multiple biological processes. The functional gene $A S P 3$, whose expression largely decreased $\left(\log _{2}\right.$ FC: $\left.-10 \sim-12\right)$, was involved in both processes of response to stress (GO: 0006950) and cellular nitrogen compound metabolism (GO: 0034641) (Fig. 2C). ASP3 was also involved in cyanoamino acid metabolism (KEGG Pathway: sce00460), the only pathway significantly enriched by the KEGG analysis, suggesting ASP3 may be one of the key genes regulating multiple-tolerant phenotypes of S. cerevisiae (Fig. 2D). To reveal the relationship among DEGs and to find the core regulatory target genes, protein-protein interaction network analysis was performed for the 28 shared DEGs. As shown in Fig. 2E, gene ENA5 ( $\left.\log _{2} \mathrm{FC}: 2 \sim 16\right)$ was located at the core of the network and had strong relationships with other DEGs. ENA5 encodes a P-type ATPase (extrudes $\mathrm{Na}^{+}$probably in exchange for $\mathrm{H}^{+}$), which may assist the efflux of sodium ions, thus reducing cytotoxicity [26]. It could be one key functional gene responsible for regulating multiple-tolerant phenotypes of $S$. cerevisiae.

Six DEGs with unknown function (putative protein with unknown function in Saccharomyces Genome Database) in 28 shared DEGs were all significantly down-regulated (Fig. 2F). Among these six DEGs, the expression of DEGs named YOL162W $\left(\log _{2} \mathrm{FC}:-8 \sim-11\right), \quad Y O L 163 W\left(\log _{2} \mathrm{FC}:-8 \sim-10\right)$ and YOR012W $\left(\log _{2} \mathrm{FC}:-8 \sim-10\right)$ decreased more than other three DEGs, suggesting they may have a greater impact on the tolerance phenotype [27]. Genes $Y O L 162 \mathrm{~W}$ and $Y O L 163 \mathrm{~W}$ have high sequence similarity and were proposed to have similar function [28]. Hence, $Y O L 162 \mathrm{~W}$ and $Y O R 012 \mathrm{~W}$ were selected as candidate genes to explore their effects on multiple-tolerant phenotypes of $S$. cerevisiae.

Crz1p $\left(\log _{2} \mathrm{FC}: 1 \sim 2\right)$ and Tos8p ( $\left.\log _{2} \mathrm{FC}:-9 \sim-13\right)$ were two transcriptional factors (TFs) found in the 28 shared DEGs (Fig. 2G). The regulatory relationship between these two TFs and the 28 shared DEGs was explored through YEASTRACT database. The results showed that the DEGs including SPO24, ENA5, WSC2, HSP150, YOL162W, and YOL163W among the 28 shared DEGs were potentially regulated by Crz1p. DEGs of GEX2 and YDR222W were potentially regulated by Tos8p. Therefore, Crz1p and Tos8p may be 

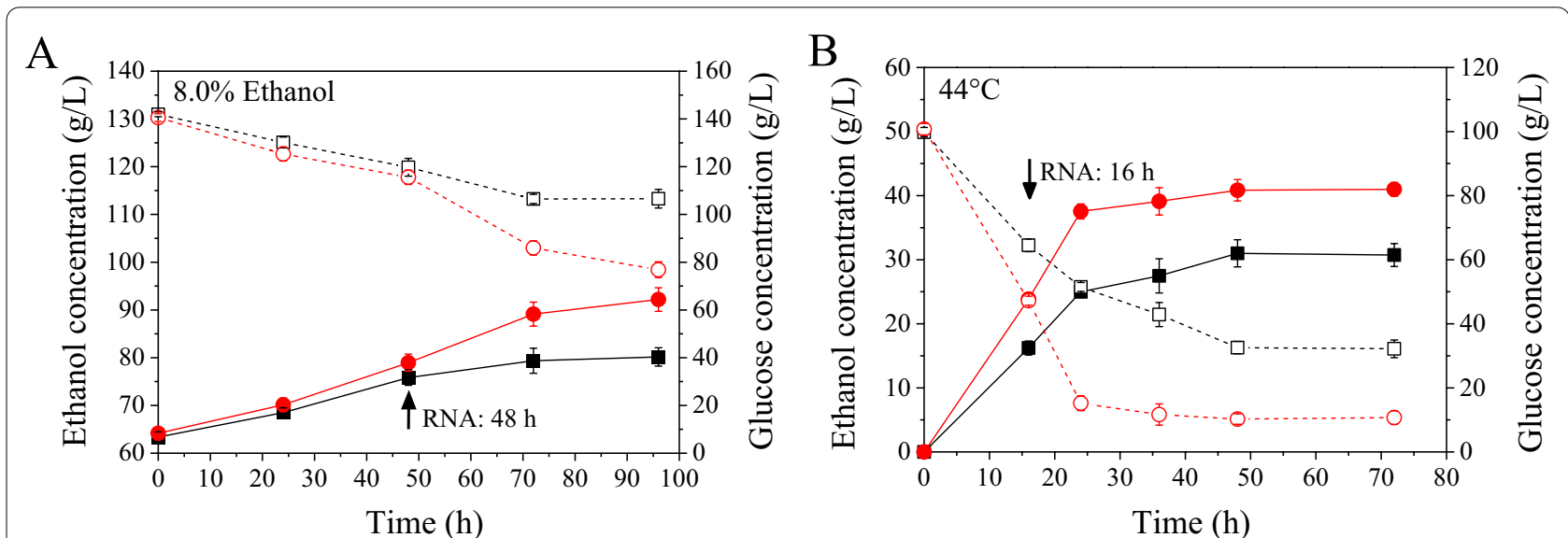

$\mathrm{C}$

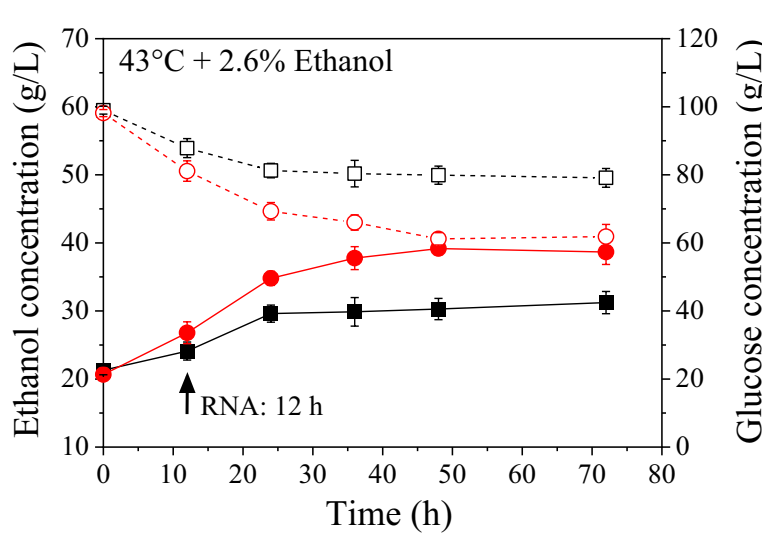

$\mathrm{D}$
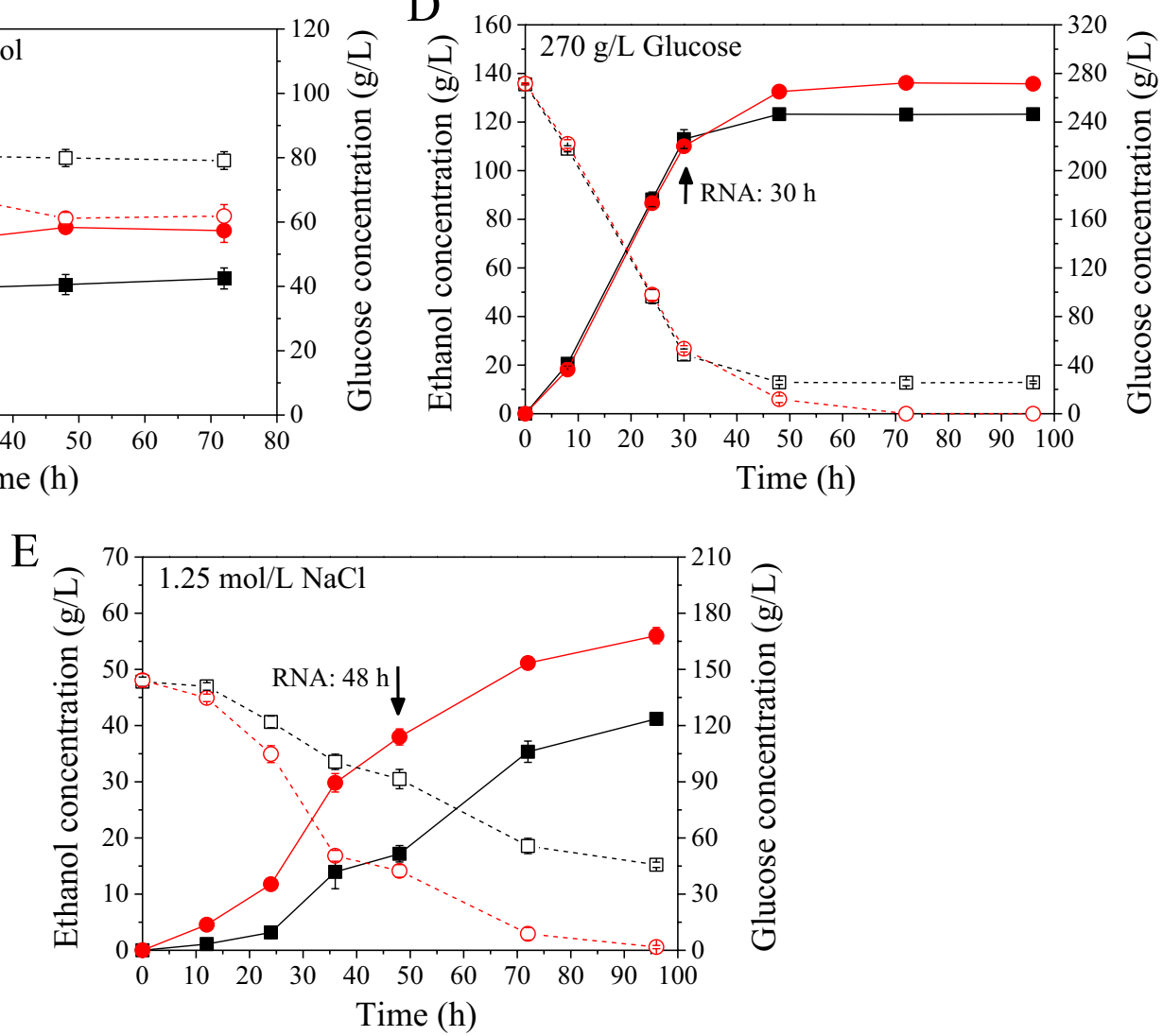

Fig. 1 Fermentation characteristics under five stress conditions. Fermentation kinetics (A-E) of KF-7 (open squares: glucose; closed squares: ethanol) and E-158 (open circles: glucose; closed circles: ethanol) were shown. Data are averages of three independent experiments (error bars represent SD)

(See figure on next page.)

Fig. 2 A comprehensive selection of key genes potentially related to the multiple stress-tolerant phenotypes. A DEGs under five stress conditions; B Venn diagram of DEGs under the five stress conditions, including 28 shared DEGs; C GO enrichment analyses of 28 shared DEGs; D the pathway of cyanoamino acid metabolism; E protein-protein interaction network of 28 shared DEGs. In the plot, the bluer the circle, the greater the contribution of the gene, the thicker the line, the stronger the interaction between the two genes; $\mathbf{F}$ Relative expression level of the DEGs of unknown function in 28 shared DEGs; G DEGs regulated by the two identified TFs in 28 shared DEGs 
A

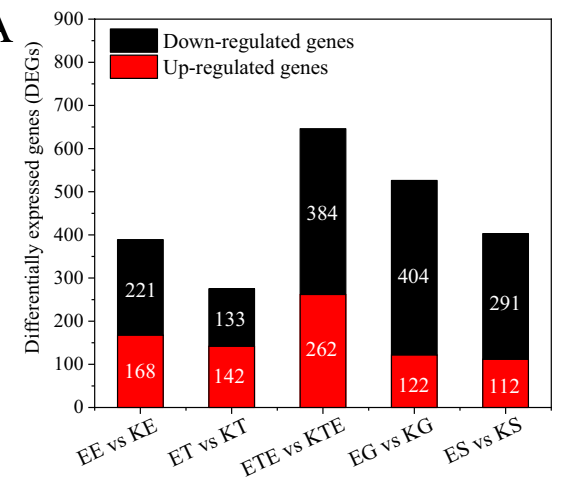

$\mathrm{C}$

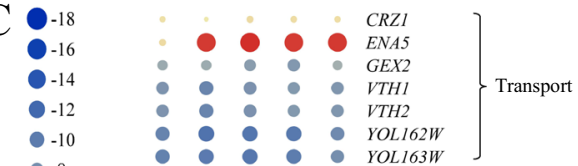

- -8 ○ $\bigcirc \bigcirc$

- -6 CRZI

- $-4 \div \div$ WSC2

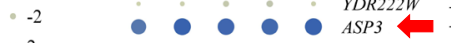

2 C CRZI

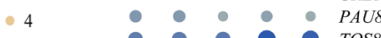

$66 ?$ ? 6 ?

$8 \quad \because \begin{aligned} & A G A 1 \\ & M F(A L P H A) 2\end{aligned}$

○ $10 \bullet \bullet \bullet-P A U 8$

12

14

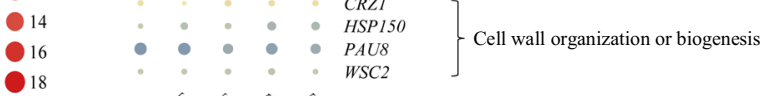

Log2 $2 \mathrm{FC}$

Response to stress

Cellular nitrogen compound metabolic proces

$\mathrm{E}$

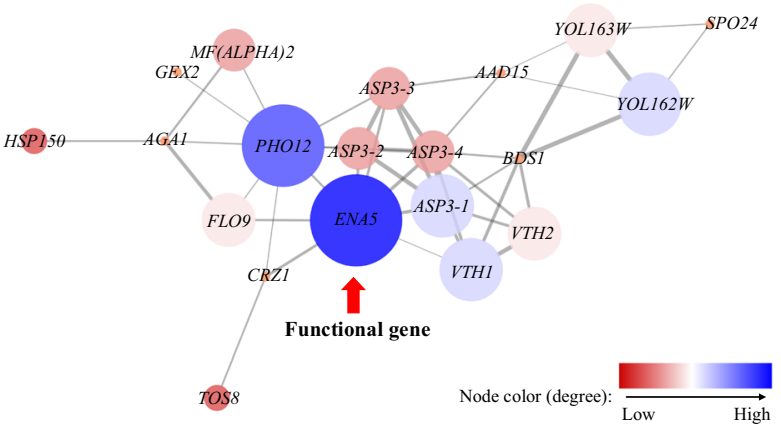

B

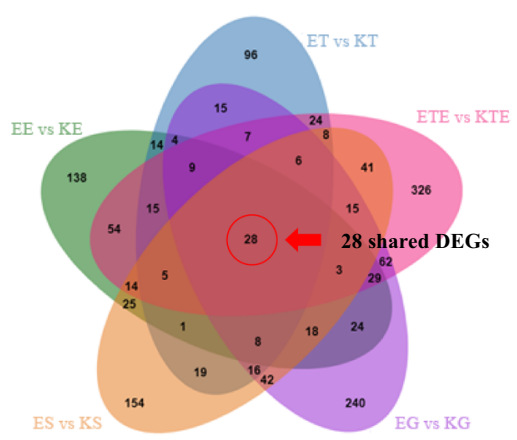

$\mathrm{D}$

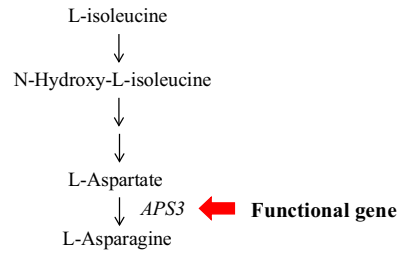

$\mathrm{F}$

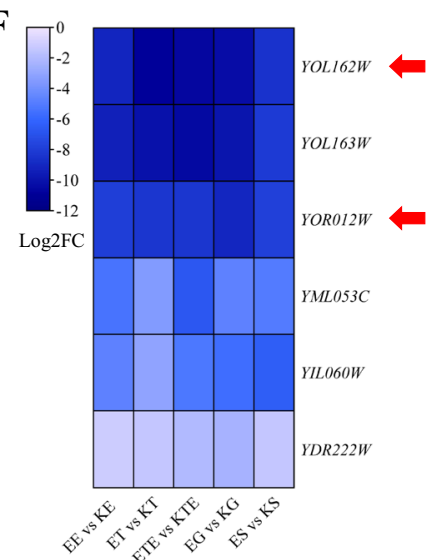

G
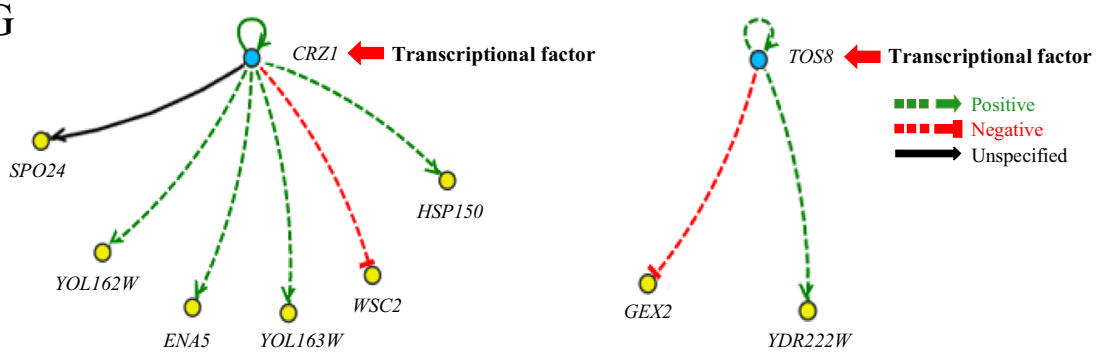

Fig. 2 (See legend on previous page.) 
key TFs regulating multiple-tolerant phenotypes of $S$. cerevisiae.

\section{Growth and fermentation abilities of engineered strains using original strain $\mathrm{KF}-7$ as host}

To experimentally verified whether the identified key DEGs are responsible for the multiple-tolerant phenotypes in strain E-158, using its original strain KF-7 as a host, genes $C R Z 1$ and $E N A 5$ were over expressed, and genes ASP3, TOS8, YOL162W, and YOR012W were knocked out to result in strains KF-7-CRZ1, KF-7-ENA5, KF-7 $\Delta$ ASP3, KF-7 $\Delta$ TOS8, KF-7 $\Delta$ YOL162W, and KF-7 $\triangle$ YOR012W, respectively. The growth of these engineered strains under different stress conditions was compared with that of KF-7 through the spot assay (Fig. 3). Under the condition without stress, strains showed similar growth capacities. When exposed to $13 \%$ (v/v) ethanol, all strains, except strain KF-7-CRZ1, grew better than KF-7. Under the heat stress, strain KF-7 $\triangle$ YOL162W did not grow when the temperature was $44{ }^{\circ} \mathrm{C}$. However, the growth of other strains was significantly better than that of KF-7. When the spot assay was respectively performed under the osmotic stress conditions, i.e., $400 \mathrm{~g} / \mathrm{L}$ glucose and $3 \mathrm{~mol} / \mathrm{L}$ sorbitol, strains KF-7-CRZ1, KF-7-ENA5, KF-7 $\triangle \mathrm{ASP} 3, \mathrm{KF}-7 \Delta \mathrm{TOS} 8$, and KF-7 $\Delta$ YOR012W grew better than KF-7, but there was no significant difference between KF-7 $\triangle$ YOL162W and KF-7.

To evaluate the ability of ethanol tolerance of the engineered strains, batch fermentations were performed using YPD150 media with $8.0 \%(\mathrm{v} / \mathrm{v})$ initial ethanol concentration (Fig. 4A). Except for KF-7-CRZ1 and KF-7 $\triangle Y$ YOL162W, the other strains produced significantly $(P<0.05)$ more ethanol than KF-7 (Table 1$)$. After 96-h fermentation, the order of the final ethanol concentrations produced by these strains was as follows: $\quad$ KF-7-ENA5 $>$ KF-7 $\Delta$ ASP3 $>$ KF-7 $\Delta$ YOR012W > KF-7 $\Delta$ TOS8 $>$ KF-7 $\Delta$ YOL162W $>$ KF-7 $>$ KF-7-CRZ1. Th e ethanol concentration of KF-7-ENA5 was the highest

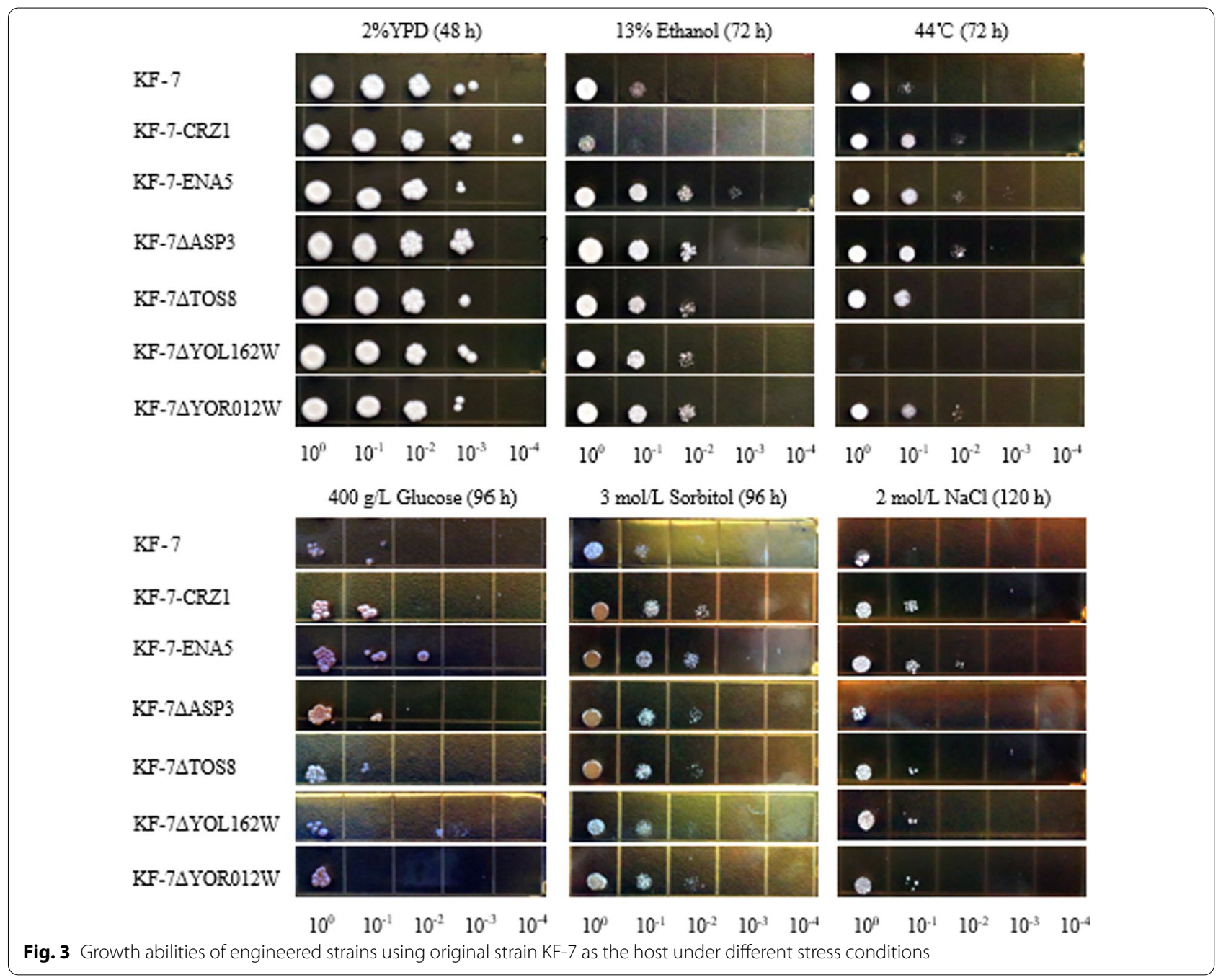



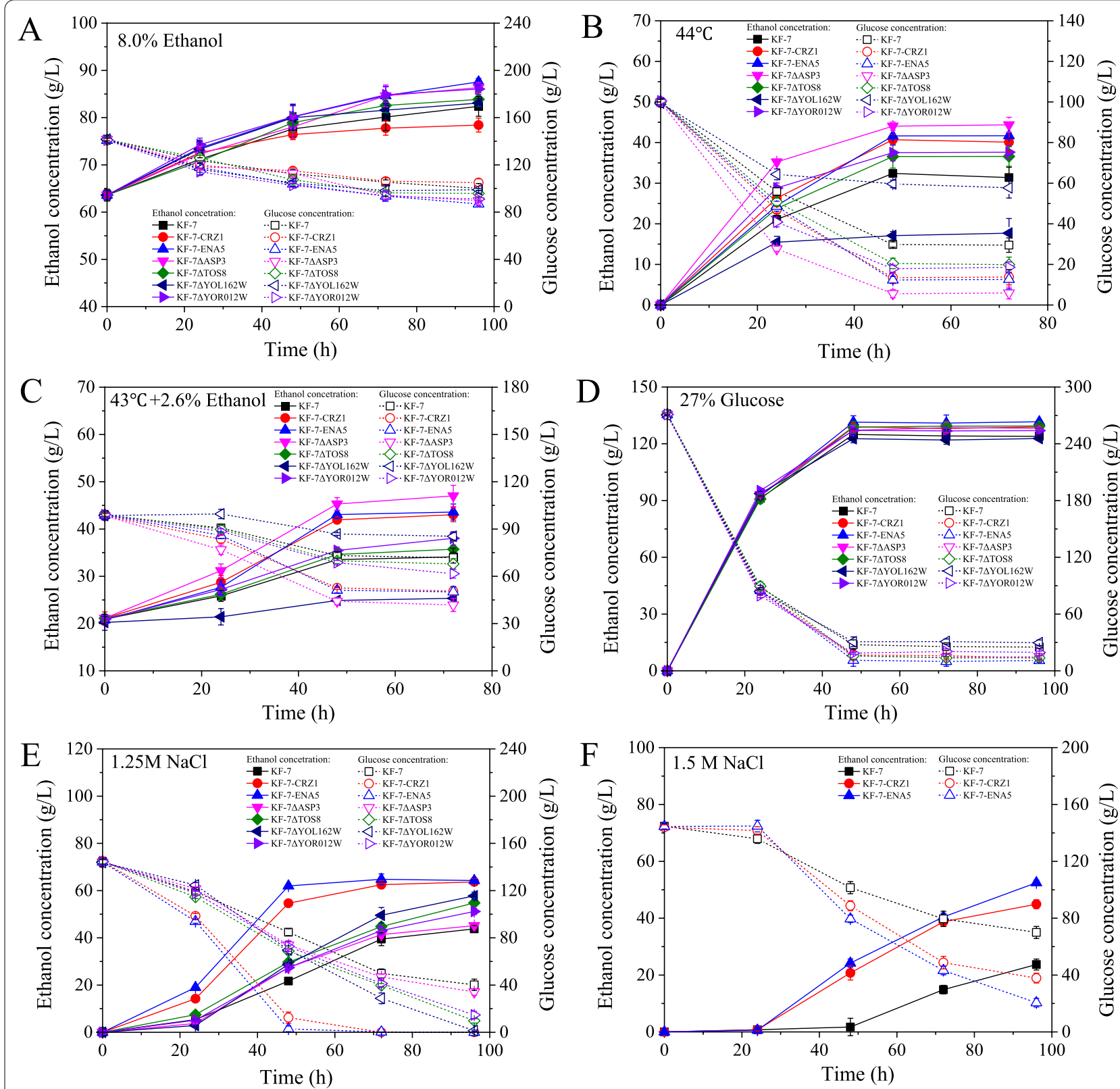

Fig. 4 Fermentation abilities of engineered strains using original strain KF-7 as the host under five stress conditions. A $8.0 \%$ initial ethanol; B $44{ }^{\circ} \mathrm{C}$; C $43^{\circ} \mathrm{C}$ with 2.6\% initial ethanol; D $270 \mathrm{~g} / \mathrm{L}$ glucose; E $1.25 \mathrm{~mol} / \mathrm{L} \mathrm{NaCl} ; \mathbf{F} 1.5 \mathrm{~mol} / \mathrm{L} \mathrm{NaCl}$. Data are averages of three independent experiments (error bars represent SD)

$(23.96 \pm 0.73 \mathrm{~g} / \mathrm{L})$, which was $27.57 \%$ higher than that of KF-7 (18.79 $\pm 2.11 \mathrm{~g} / \mathrm{L})$ (Table 1).

During the batch fermentations at $44{ }^{\circ} \mathrm{C}$, the ethanol concentration of KF-7 $\triangle$ YOL162W was only $56.39 \%$ of that of KF-7, but the ethanol concentrations of other strains were significantly $(P<0.05)$ higher than that of KF-7 (Fig. 4B, Table 1). Among them, KF-7 $\triangle \mathrm{ASP} 3$ $(44.37 \pm 1.86 \mathrm{~g} / \mathrm{L})$ had the highest ethanol production, which was $41.35 \%$ higher than KF-7 $(31.39 \pm 2.54 \mathrm{~g} / \mathrm{L})$.
Meanwhile, the ethanol concentration of KF-7 $\triangle \mathrm{ASP} 3$ $(25.91 \pm 2.24 \mathrm{~g} / \mathrm{L})$ was $99.31 \%$ higher than that of KF-7 $(13.00 \pm 1.84 \mathrm{~g} / \mathrm{L})$ under two stresses of ethanol and heat (Fig. 4C, Table 1).

VHG fermentations were conducted using YP medium with $271.09 \mathrm{~g} / \mathrm{L}$ glucose concentration. Except for strain KF-7 $\Delta$ YOL162W, the ethanol concentrations of other strains were increased by $2.45 \%$ $(\mathrm{KF}-7 \Delta \mathrm{YOR} 012 \mathrm{~W}) \sim 6.24 \% \quad$ (KF-7-ENA5) $\quad$ compared 
Table 1 Comparisons of fermentation performance of engineered strains using original strain KF-7 as the host

\begin{tabular}{|c|c|c|c|c|c|c|}
\hline Indexes & Strains & $\begin{array}{l}8.0 \%(v / v) \\
\text { Initial ethanol } \\
\text { (YPD150) }\end{array}$ & $\begin{array}{l}44^{\circ} \mathrm{C} \\
\text { (YPD100) }\end{array}$ & $\begin{array}{l}43^{\circ} \mathrm{C}+2.6 \%(\mathrm{v} / \mathrm{v}) \\
\text { Initial ethanol } \\
\text { (YPD100) }\end{array}$ & $\begin{array}{l}\text { 27\% Glucose } \\
\text { (YPD270) }\end{array}$ & $\begin{array}{l}1.25 \mathrm{M} \mathrm{NaCl} \\
\text { (YPD150) }\end{array}$ \\
\hline & KF-7 & $18.79 \pm 2.11 \mathrm{c}$ & $31.39 \pm 2.54 c$ & $13.00 \pm 1.84 b$ & $123.92 \pm 0.79 c$ & $43.78 \pm 1.37 d$ \\
\hline \multirow{7}{*}{$\begin{array}{l}\text { Final generated ethanol concentration } \\
(\mathrm{g} / \mathrm{L})\end{array}$} & KF-7-CRZ1 & $14.82 \pm 1.48 \mathrm{~d}$ & $40.11 \pm 2.42 \mathrm{ab}$ & $21.93 \pm 1.49 a$ & $128.99 \pm 1.05 b$ & $63.66 \pm 1.50 a$ \\
\hline & KF-7-ENA5 & $23.96 \pm 0.73 a$ & $41.69 \pm 0.66 a b$ & $22.50 \pm 1.70 \mathrm{a}$ & $131.65 \pm 0.99 a$ & $64.26 \pm 1.12 \mathrm{a}$ \\
\hline & $\mathrm{KF}-7 \triangle \mathrm{ASP} 3$ & $22.76 \pm 1.12 \mathrm{ab}$ & $44.37 \pm 1.86 a$ & $25.91 \pm 2.24 a$ & $128.19 \pm 0.69 b$ & $45.16 \pm 1.17 d$ \\
\hline & $\mathrm{KF}-7 \triangle \mathrm{TOS} 8$ & $20.26 \pm 1.57 a b$ & $36.58 \pm 2.19 b c$ & $14.63 \pm 1.79 b$ & $129.40 \pm 0.96 a b$ & $54.78 \pm 0.81 b c$ \\
\hline & $\mathrm{KF}-7 \Delta \mathrm{YOL} 162 \mathrm{~W}$ & $19.49 \pm 0.94 b c$ & $17.70 \pm 3.60 d$ & $4.24 \pm 1.26 c$ & $122.80 \pm 1.19 c$ & $57.77 \pm 1.62 b$ \\
\hline & $\mathrm{KF}-7 \triangle \mathrm{YOR} 012 \mathrm{~W}$ & $22.45 \pm 1.11 \mathrm{ab}$ & $37.63 \pm 1.54 b c$ & $16.94 \pm 1.43 b$ & $126.95 \pm 1.99 b c$ & $51.16 \pm 1.33 c$ \\
\hline & $\mathrm{KF}-7$ & $100.12 \pm 4.07 a b$ & $29.51 \pm 3.57 b$ & $71.80 \pm 3.41 b$ & $25.09 \pm 1.49 a$ & $40.18 \pm 4.81 \mathrm{a}$ \\
\hline \multirow[t]{6}{*}{ Residual glucose (g/L) } & KF-7-CRZ1 & $105.01 \pm 3.12 \mathrm{a}$ & $13.75 \pm 3.78 \mathrm{~cd}$ & $50.59 \pm 2.80 \mathrm{~d}$ & $13.48 \pm 2.58 \mathrm{c}$ & $0.00 \pm 0.00 c$ \\
\hline & KF-7-ENA5 & $86.88 \pm 1.55 d$ & $12.62 \pm 4.69 \mathrm{~cd}$ & $50.10 \pm 3.37 d$ & $10.90 \pm 1.88 \mathrm{c}$ & $0.00 \pm 0.00 c$ \\
\hline & $\mathrm{KF}-7 \triangle \mathrm{ASP} 3$ & $89.53 \pm 1.29 \mathrm{~cd}$ & $5.89 \pm 2.90 d$ & $41.76 \pm 4.16 \mathrm{~d}$ & $15.05 \pm 1.31 b c$ & $34.11 \pm 2.72 \mathrm{a}$ \\
\hline & $\mathrm{KF}-7 \Delta \mathrm{TOS} 8$ & $95.74 \pm 2.71 b c$ & $19.88 \pm 3.72 \mathrm{bc}$ & $67.85 \pm 3.33 b c$ & $13.74 \pm 1.91 \mathrm{c}$ & $9.76 \pm 1.88 \mathrm{~b}$ \\
\hline & $\mathrm{KF}-7 \Delta \mathrm{YOL} 162 \mathrm{~W}$ & $98.98 \pm 1.86 a b$ & $57.75 \pm 5.06 a$ & $85.36 \pm 2.35 a$ & $29.66 \pm 2.92 a$ & $1.36 \pm 0.53 c$ \\
\hline & $\mathrm{KF}-7 \triangle \mathrm{YOR} 012 \mathrm{~W}$ & $90.97 \pm 1.13 \mathrm{~cd}$ & $18.56 \pm 2.63 c$ & $61.66 \pm 2.84 c$ & $19.48 \pm 1.17 b$ & $14.66 \pm 3.09 b$ \\
\hline \multirow{7}{*}{$\begin{array}{l}\text { Ethanol yield (g ethanol/g consumed } \\
\text { glucose) }\end{array}$} & $\mathrm{KF}-7$ & $0.45 \pm 0.01 a$ & $0.45 \pm 0.01 b c$ & $0.47 \pm 0.01 a$ & $0.50 \pm 0.01 a$ & $0.42 \pm 0.02 a b$ \\
\hline & KF-7-CRZ1 & $0.41 \pm 0.01 b$ & $0.46 \pm 0.00 \mathrm{ab}$ & $0.46 \pm 0.01 a$ & $0.50 \pm 0.00 a$ & $0.44 \pm 0.02 a b$ \\
\hline & KF-7-ENA5 & $0.44 \pm 0.00 \mathrm{a}$ & $0.48 \pm 0.02 \mathrm{a}$ & $0.46 \pm 0.01 a$ & $0.50 \pm 0.01 a$ & $0.45 \pm 0.01 a$ \\
\hline & $\mathrm{KF}-7 \triangle \mathrm{ASP} 3$ & $0.44 \pm 0.00 a$ & $0.47 \pm 0.00 a b$ & $0.46 \pm 0.01 a$ & $0.50 \pm 0.00 a$ & $0.41 \pm 0.00 \mathrm{bc}$ \\
\hline & $\mathrm{KF}-7 \Delta \mathrm{TOS} 8$ & $0.44 \pm 0.02 a$ & $0.46 \pm 0.01 a b$ & $0.47 \pm 0.01 a$ & $0.49 \pm 0.01 a$ & $0.41 \pm 0.00 \mathrm{bc}$ \\
\hline & $\mathrm{KF}-7 \Delta \mathrm{YOL} 162 \mathrm{~W}$ & $0.46 \pm 0.01 a$ & $0.42 \pm 0.01 c$ & $0.32 \pm 0.02 b$ & $0.49 \pm 0.01 a$ & $0.41 \pm 0.01 b c$ \\
\hline & $\mathrm{KF}-7 \triangle \mathrm{YOR} 012 \mathrm{~W}$ & $0.45 \pm 0.01 a$ & $0.46 \pm 0.01 \mathrm{ab}$ & $0.45 \pm 0.02 a$ & $0.50 \pm 0.01 a$ & $0.39 \pm 0.01 c$ \\
\hline
\end{tabular}

The data in the table are those at the end of fermentation. Values indicate mean \pm standard deviation of three biological replications. Values followed by different lowercase letters in the same column indicate significant differences at the level of $P<0.05$ (Tukey-test) among strains. Same lowercase letters, no difference. KF-7-CRZ1: overexpression of TF Crz1p in KF-7; KF-7-ENA5: overexpression of ENA5 in KF-7; KF-7 $\triangle$ ASP3: Knockout ASP3 in KF-7; KF-7 $\triangle$ TOS8: Knockout TOS8 in KF-7; KF-7 YYOL162W: Knockout YOL162W in KF-7; KF-7DYOR012W: Knockout YOR012W in KF-7

with that of KF-7 (Fig. 4D, Table 1). All strains had improved fermentation performance when fermenting YPD150 medium supplemented with $1.25 \mathrm{~mol} / \mathrm{L}$ (7.31\%) $\mathrm{NaCl}$ (Fig. 4E). Especially, after 96-h fermentation, strains KF-7-CRZ1 and KF-7-ENA5 utilized all glucose, but the residual glucose was $43.78 \pm 1.37 \mathrm{~g} / \mathrm{L}$ for KF-7 (Table 1). When the concentration of $\mathrm{NaCl}$ was increased to $1.5 \mathrm{~mol} / \mathrm{L}$, strains KF-7-CRZ1 and KF7-ENA5 showed high ethanol production and glucose consumption rates (Fig. 4F). The final ethanol concentrations were $52.48 \pm 0.97 \mathrm{~g} / \mathrm{L}$ and $44.93 \pm 1.58 \mathrm{~g} / \mathrm{L}$, which were $121.42 \%$ and $89.56 \%$ higher than those of KF-7, respectively.

\section{Growth and fermentation abilities of engineered strains using resistant strain $\mathrm{E}-158$ as host}

Since the overexpression of ENA5 or CRZ1 significantly improved multiple stress-tolerance of the original strain KF-7, the effects of overexpression of these two genes on resistant strain E-158 were further explored. Overexpression of ENA5 and CRZ1 using E-158 as host resulted in strains KF-7-CRZ1 and E-158-ENA5, respectively. The growth of E-158-ENA5 was significantly better than that of E-158 in the presence of $13 \%(\mathrm{v} / \mathrm{v})$ ethanol, while the growth of E-158-CRZ1 was poor (Fig. 5). E-158CRZ1 and E-158-ENA5 grew better than E-158 under heat stress at $44{ }^{\circ} \mathrm{C}$. Under the high osmotic conditions of $400 \mathrm{~g} / \mathrm{L}$ glucose, $3 \mathrm{~mol} / \mathrm{L}$ sorbitol, or $2 \mathrm{~mol} / \mathrm{L} \mathrm{NaCl}$, the growths of E-158-CRZ1 and E-158-ENA5 were better than that of E-158. Particularly, under $2 \mathrm{~mol} / \mathrm{L} \mathrm{NaCl}$ stress, both the engineered strains showed excellent growth capacities.

Batch fermentations of E-158-CRZ1 and E-158-ENA5 were conducted under five stress conditions. Overexpression of ENA5 further increased the ethanol tolerance of E-158. The ethanol produced by E-158-ENA5 $(32.39 \pm 1.02 \mathrm{~g} / \mathrm{L})$ was $13.09 \%$ higher than that of E-158 $(28.64 \pm 1.66 \mathrm{~g} / \mathrm{L})$ when YPD150 medium with $8.0 \%(\mathrm{v} / \mathrm{v})$ initial ethanol concentration was fermented (Fig. 6A, Table 2). However, the ethanol concentration of strain E-158-CRZ1 was lower than that of E-158.

Under fermentation at $44{ }^{\circ} \mathrm{C}$, the ethanol concentrations of E-158-CRZ1 and E-158-ENA5 were increased by $11.86 \%$ and $14.17 \%$, respectively, compared with that of E-158 (Fig. 6B, Table 2). Meanwhile, the ethanol production and glucose consumption rates of E-158-CRZ1 


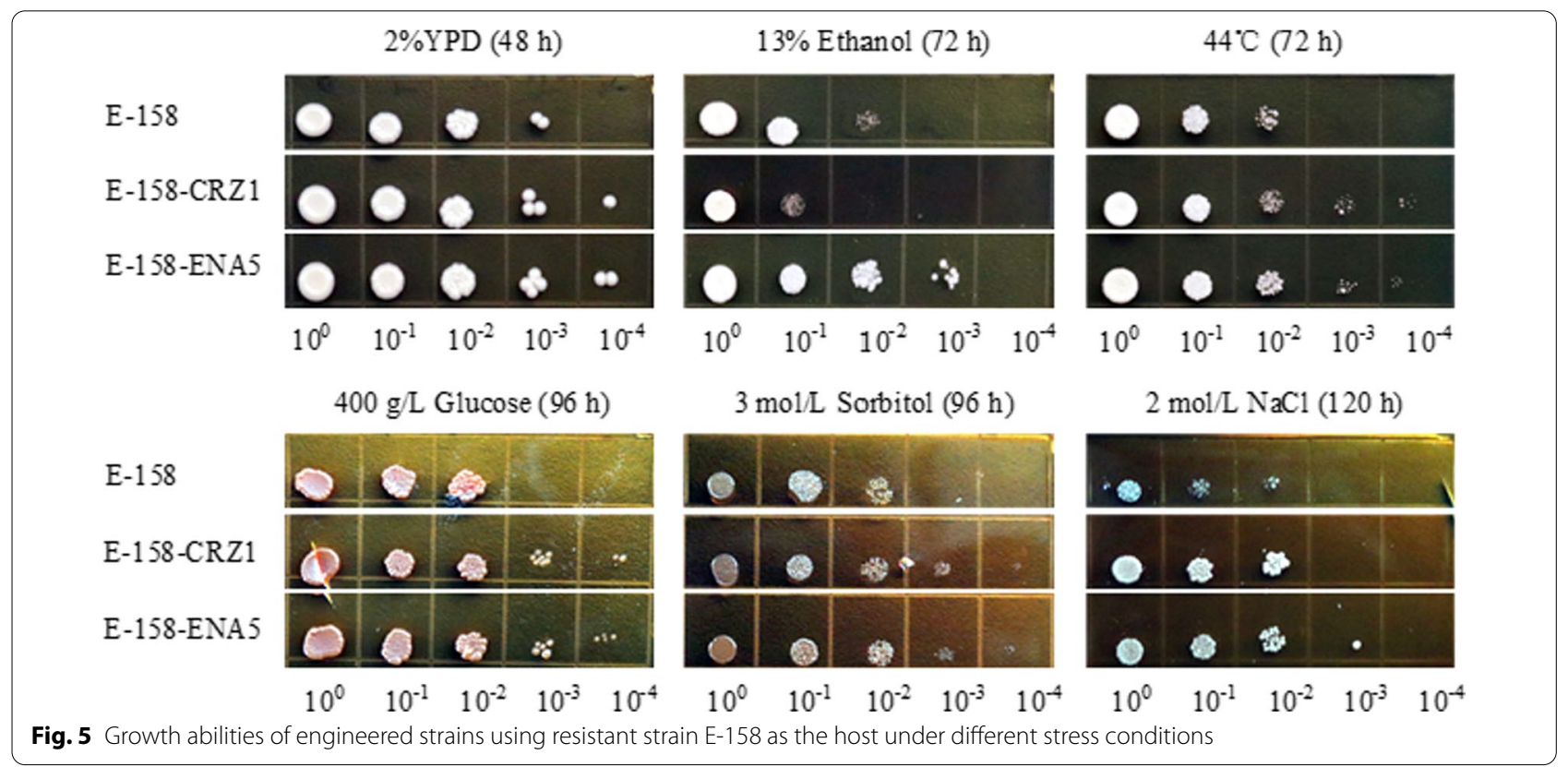

and E-158-ENA5 were significant higher $(P<0.05)$ than those of E-158 under the multiple stress of ethanol and heat, and the final ethanol concentrations produced by them were increased by about $30 \%$ compared with that of E-158 (Fig. 6C, Table 2).

When VHG fermentation was conducted under $280.72 \mathrm{~g} / \mathrm{L}$ glucose concentration, significant $(P<0.05)$ difference in the fermentation performance among the strains was not observed (Fig. 6D). However, under the fermentation condition of $1.25 \mathrm{~mol} / \mathrm{L} \mathrm{NaCl}, \mathrm{E}-158-\mathrm{CRZ1}$ and E-158-ENA5 consumed all the glucose at $72 \mathrm{~h}$, which was $24 \mathrm{~h}$ earlier than E-158 (Fig. 6E). When the concentration of $\mathrm{NaCl}$ was increased to $1.5 \mathrm{~mol} / \mathrm{L}$, the final ethanol concentrations of E-158-CRZ1 and E-158-ENA5 were $46.90 \pm 2.10 \mathrm{~g} / \mathrm{L}$ and $56.73 \pm 1.05 \mathrm{~g} / \mathrm{L}$, respectively, which were $66.73 \%$ and $101.67 \%$ higher than that of E-158 $(28.13 \pm 1.58 \mathrm{~g} / \mathrm{L})$ (Fig. 6F, Table 2). In conclusion, overexpression of ENA5 improved all kinds of stress tolerance of resistant strain E-158.

\section{Fermentation abilities of engineered strains when fermenting pretreated straw, molasses and cassava under stress conditions}

To evaluate the potential of the strains engineered in this study for industrial applications, the fermentation abilities of strains KF-7, KF-7-ENA5, E-158, and E-158-ENA5 were assessed using pretreated straw, molasses, and cassava, which are feedstocks commonly used in industrial ethanol production (Additional file 1: Tables S2, S3, S4). By SSF of pretreated straw at $42{ }^{\circ} \mathrm{C}$, the ethanol concentrations of KF-7-ENA5, E-158, and E-158-ENA5 were
$63.35 \pm 2.50 \mathrm{~g} / \mathrm{L}, 65.50 \pm 3.71 \mathrm{~g} / \mathrm{L}$, and $68.40 \pm 1.59 \mathrm{~g} / \mathrm{L}$, respectively, which were increased by $13.35 \%, 17.19 \%$, and $22.38 \%$ individually, compared with that of the original strain KF-7 (55.89 $\pm 2.68 \mathrm{~g} / \mathrm{L})$ (Fig. 7A, Additional file 1: Fig. S1A, B). The engineered strains also showed much higher ethanol yields (Additional file 1: Table S5). These results indicated that the overexpression of ENA5 improved the fermentation capacity of the strains under high temperatures.

When the molasses with $270.91 \mathrm{~g} / \mathrm{L}$ total sugar was fermented, the final ethanol concentrations of KF-7-ENA5, E-158, and E-158-ENA5 were 22.32\%-27.31\% higher than that of KF-7, and the strain E-158-ENA5 had the highest ethanol concentration of $98.28 \mathrm{~g} / \mathrm{L}$ (Fig. 7B, Additional file 1: Fig. S1C). When cassavas with a solid content of $35 \%$ were used for SSF at $33{ }^{\circ} \mathrm{C}$, the ethanol concentrations of strains KF-7-ENA5, E-158, and E-158-ENA5 were $6.50 \%, 11.01 \%, 14.08 \%$ respectively after 96 -h fermentation, higher than that of KF-7, and the ethanol concentration produced by strain E-158-ENA5 was 138.43 g/L (Fig. 7C, Additional file 1: Fig. S1D). These results suggested that the overexpression of ENA5 simultaneously enhanced tolerance of the strains to the heat, ethanol, and osmosis when different industrial feedstocks were fermented.

\section{Discussion}

To find target genes that can increase the multiple stress-tolerant ability of $S$. cerevisiae suitable for various industrial feedstocks is still challenging because of the molecular regulation complexity of multiple 

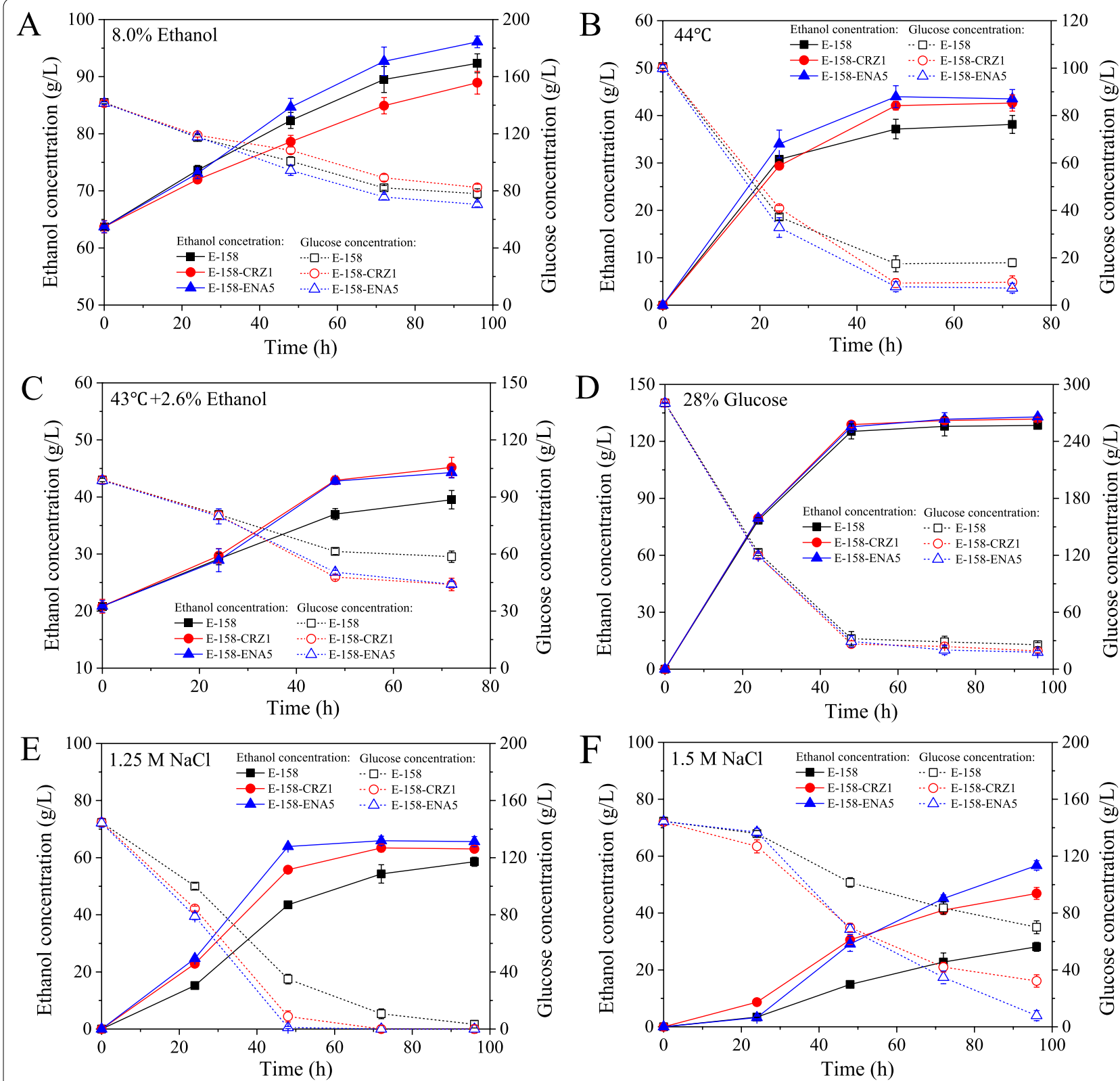

Fig. 6 Fermentation abilities of engineered strains using resistant strain E-158 as the host under five stress conditions. A $8.0 \%$ initial ethanol; B $44{ }^{\circ} \mathrm{C}$; C $43{ }^{\circ} \mathrm{C}$ with $2.6 \%$ initial ethanol; D $280 \mathrm{~g} / \mathrm{L}$ glucose; $\mathbf{E} 1.25 \mathrm{~mol} / \mathrm{L} \mathrm{NaCl} ; \mathbf{F} 1.5 \mathrm{~mol} / \mathrm{L} \mathrm{NaCl}$. Data are averages of three independent experiments (error bars represent SD)

stress-tolerant phenotypes. Presently, researchers have reported that single tolerance to ethanol or high temperature of $S$. cerevisiae can be significantly improved by over expressing or knocking out some genes or TFs [23, 24], however, researches on screening key genes responsible for enhancing the multiple stress-tolerance of industrial S. cerevisiae are absent. In our previous study, a multiple stress-tolerant strain E-158 was obtained by mutagenesis and hybridization using KF-7 as the starting strain [18].
In the present study, by comparing the transcriptomes of E-158 and KF-7, 28 DEGs were found shared under five stress conditions (Fig. 2). Six of them were mined and all of them were found to be associated with multiple stresstolerant phenotypes of $S$. cerevisiae.

Among the six DEGs, ENA5 was the most prominent in the multiple stress-tolerance improvement. To date, no report has revealed the relationship between ENA5 and the stress tolerance phenotypes of $S$. cerevisiae. Our 
Table 2 Comparisons of fermentation performance of engineered strains using resistant strain E-158 as the host

\begin{tabular}{|c|c|c|c|c|c|c|}
\hline Indexes & Strains & $\begin{array}{l}8.0 \%(v / v) \\
\text { Initial ethanol } \\
\text { (YPD150) }\end{array}$ & $\begin{array}{l}44^{\circ} \mathrm{C} \\
\text { (YPD100) }\end{array}$ & $\begin{array}{l}43^{\circ} \mathrm{C}+2.6 \%(\mathrm{v} / \mathrm{v}) \\
\text { Initial ethanol } \\
\text { (YPD100) }\end{array}$ & $\begin{array}{l}\text { 28\% Glucose } \\
\text { (YPD280) }\end{array}$ & $\begin{array}{l}1.5 \mathrm{M} \mathrm{NaCl} \\
\text { (YPD150) }\end{array}$ \\
\hline \multirow[t]{4}{*}{ Final generated ethanol concentration $(\mathrm{g} / \mathrm{L})$} & E-158 & $28.64 \pm 1.66 \mathrm{bc}$ & $38.12 \pm 1.90 \mathrm{~b}$ & $18.66 \pm 1.62 b$ & $128.40 \pm 1.17 b$ & $28.13 \pm 1.58 \mathrm{c}$ \\
\hline & $\mathrm{E}-158-\mathrm{CRZ1}$ & $25.24 \pm 1.99 c$ & $42.64 \pm 1.71 \mathrm{a}$ & $24.34 \pm 1.76 a$ & $131.77 \pm 0.79 a$ & $46.90 \pm 2.10 \mathrm{~b}$ \\
\hline & E-158-ENA5 & $32.39 \pm 1.02 \mathrm{a}$ & $43.52 \pm 1.17 a$ & $23.43 \pm 0.95 a$ & $132.90 \pm 1.80 \mathrm{a}$ & $56.73 \pm 1.05 a$ \\
\hline & $\mathrm{E}-158$ & $78.00 \pm 3.40 a$ & $17.91 \pm 1.72 \mathrm{a}$ & $56.25 \pm 3.00 \mathrm{a}$ & $25.75 \pm 2.22 \mathrm{a}$ & $72.47 \pm 4.53 a$ \\
\hline \multirow[t]{2}{*}{ Residual glucose (g/L) } & E-158-CRZ1 & $82.34 \pm 2.35 a$ & $9.70 \pm 2.66 b$ & $43.99 \pm 3.30 b$ & $19.21 \pm 1.95 b$ & $34.24 \pm 4.36 b$ \\
\hline & E-158-ENA5 & $70.44 \pm 1.74 b$ & $7.21 \pm 2.03 b$ & $44.13 \pm 1.40 b$ & $17.79 \pm 2.79 b$ & $8.75 \pm 2.54 \mathrm{c}$ \\
\hline \multirow{3}{*}{$\begin{array}{l}\text { Ethanol yield } \\
\text { (g ethanol/g consumed glucose) }\end{array}$} & $\mathrm{E}-158$ & $0.45 \pm 0.01 \mathrm{ab}$ & $0.46 \pm 0.00 \mathrm{a}$ & $0.44 \pm 0.00 a$ & $0.50 \pm 0.00 \mathrm{a}$ & $0.40 \pm 0.01 b$ \\
\hline & E-158-CRZ1 & $0.43 \pm 0.01 b$ & $0.47 \pm 0.01 a$ & $0.44 \pm 0.01 a$ & $0.50 \pm 0.01 a$ & $0.43 \pm 0.00 a$ \\
\hline & E-158-ENA5 & $0.46 \pm 0.01 a$ & $0.47 \pm 0.01 a$ & $0.43 \pm 0.01 a$ & $0.50 \pm 0.01 a$ & $0.42 \pm 0.01 a$ \\
\hline
\end{tabular}

The data in the table are those at the end of fermentation. Values indicate mean \pm standard deviation of three biological replications. Values followed by different lowercase letters in the same column indicate significant differences at the level of $P<0.05$ (Tukey-test) among strains. Same lowercase letters, no difference. E-158CRZ1: Overexpression of TF Crz1p in E-158; E-158-ENA5: Overexpression of ENA5 in E-158
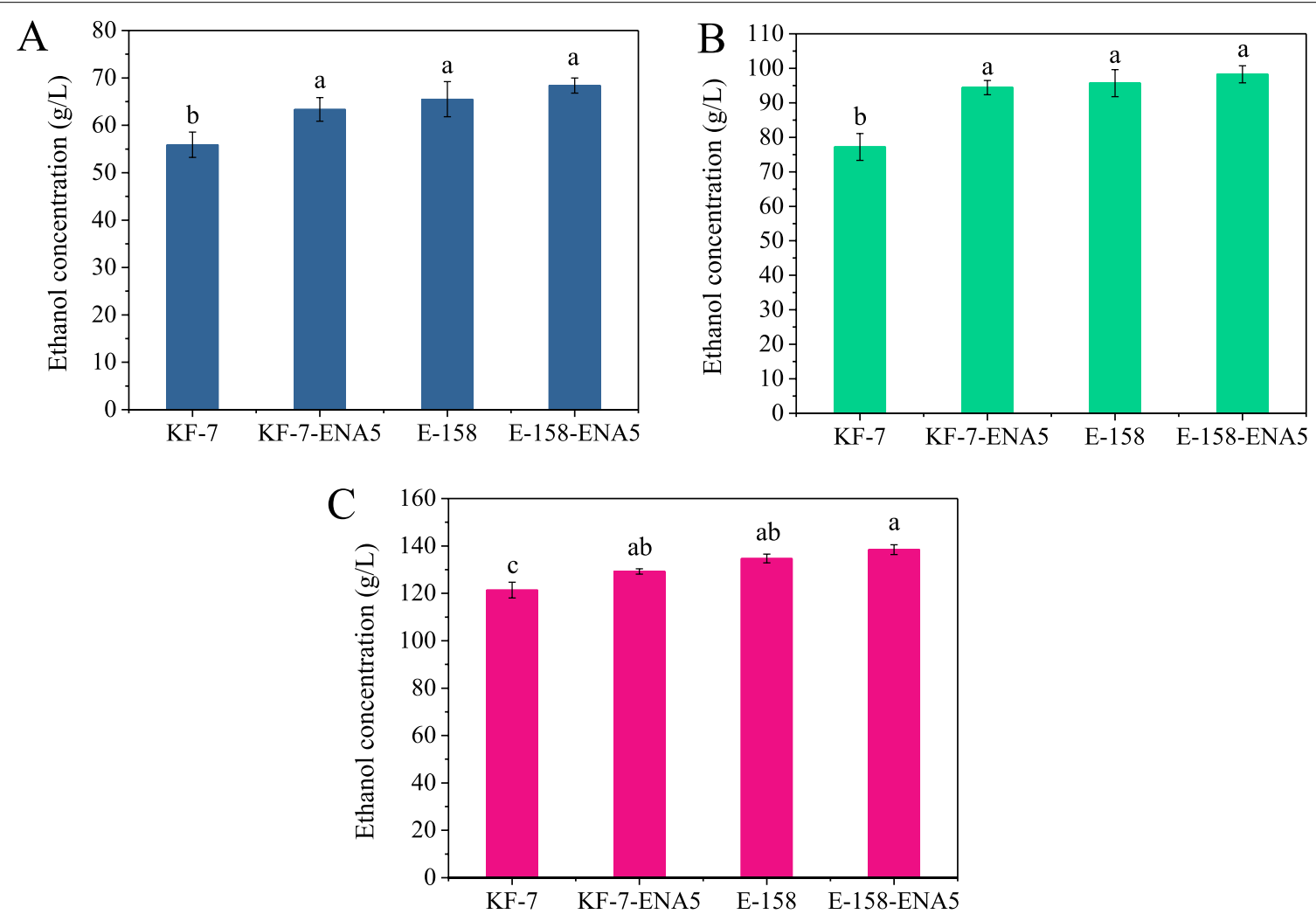

Fig. 7 Fermentation results of engineered strains when pretreated straw, molasses, and cassava were fermented under stress conditions. A High-temperature SSF of pretreated straw; B VHG fermentation of molasses; C SSF of cassava with high solid content

study revealed for the first time that the overexpression of ENA5 could significantly improve the tolerance of S. cerevisiae to all kinds of stresses studied. Especially, after overexpression of ENA5, the ethanol concentrations of engineered strains were increased to about twofold under the conditions of $1.5 \mathrm{~mol} / \mathrm{L} \mathrm{NaCl}$ (Figs. 4F,
Fig. 6F). ENA5 is previously reported as encoding P-type ATPase that may assist the efflux of sodium ions [26, 29]. Therefore, the overexpression of ENA5 may reduce cytotoxicity and enhance the salt tolerance of S. cerevisiae through assisting in the efflux of sodium ions. Genes ENA1 ENA2、ENA5 are the members of a gene cluster 
encoding proteins with very similar function [30]. These genes highly expressed under high sucrose tolerance [31], which indicating ion transport is possibly important for $S$. cerevisiae to resist high osmotic stress. Nevertheless, the specific regulatory mechanism of gene ENA5 on the multiple stress-tolerant phenotypes of $S$. cerevisiae needs to be investigated in detail in the future study.

In addition to gene $E N A 5$, for the first time, gene $A S P 3$ was found having an important effect on high ethanol and high temperature stress tolerance phenotypes of $S$. cerevisiae. ASP3 is a gene cluster composed of four identical genes, i.e., ASP3-1, ASP3-2, ASP3-3, and ASP3-4, which encode L-asparaginase II [32]. Asparaginase II is a periplasmic enzyme in yeast, hydrolyzing both $\mathrm{D}$ - and L-asparagine to aspartate and ammonium cation [32]. $A S P 3$ was upregulated during nitrogen starvation to facilitate the utilization of extracellular asparagine as a source of nitrogen [33]. Nitrogen starvation could promote the synthesis of lipid and/or polyhydroxybutyrate (PHB) [34, 35]. However, the molecular regulation mechanism of the deletion of ASP3 on stress tolerance and the possible relationship between the nitrogen starvation response and the stress tolerance are still unknown, which need further investigations.

Genes of unknown function were often found expressed [36], however, no studies showed the relationship between genes of unknown function and stresstolerant phenotypes of $S$. cerevisiae. Knocking out gene YOR012W of unknown function had a limited effect on the multiple stress-tolerant phenotypes of KF-7. However, knocking out $Y O L 162 \mathrm{~W}$ significantly improved the high salt tolerance while significantly reduced the high temperature resistance of the strain KF-7. Although the function of the protein encoded by $Y O L 162 \mathrm{~W}$ is unclear, $Y O L 162 W$ had a vital relationship with the high temperature and high salt tolerance phenotypes (Table 1), the underly mechanism is worthy for further investigation.

Several studies reported that TFs are important to regulate the tolerance phenotype of $S$. cerevisiae [24, 37]. However, the relationship of the two TFs, Tos $8 p$ and Crz1p, with the multiple stress tolerances was not reported to date. Tos8p was reported to be associated with chromatin and highly expressed under meiosis and cell damage [38]. In the present study, knocking out TOS8 in original strain KF-7 increased the osmosis and high temperature tolerance phenotypes of the strain (Table 1). YEASTRACT database shows that the TF Tos8p regulates $8.0 \%$ of the genes in the genome of $S$. cerevisiae. The genes regulated by Tos $8 \mathrm{p}$ are significantly enriched in pathways of fungal-type cell wall organization or biogenesis (GO: 0071852), cation transport (GO: 0006812), and siderophore transport (GO: 0015891). However, the molecular mechanism of the deletion of TOS 8 on the improvement of multiple stress-tolerance needs further investigations. The overexpression of $C R Z 1$ significantly improved the high temperature tolerance as well as the high osmosis tolerance of the strains (Figs. 4, 6). Crz1p is a zinc finger $\mathrm{TF}$, which regulates $14.6 \%$ of the genes in the genome of $S$. cerevisiae based on YEASTRACT database. The genes regulated by Crz1p are significantly enriched in pathways of carbohydrate metabolic process (GO: 0005975), cell wall organization or biogenesis (GO: 0071554), and transmembrane transport (GO: 0055085). CRZ1 has been reported able to enhance the resistance of $S$. cerevisiae to high concentrations of cations including $\mathrm{Ca}^{2+}, \mathrm{Mn}^{2+}, \mathrm{Na}^{+}$, and $\mathrm{Li}^{+}$by regulating the genes of calcium signaling pathway [39]. Interestingly, in the present study, overexpression of CRZ1 increased not only high salt tolerance, but also high temperature and high glucose tolerance of the strains (Tables 1,2). Though there are reports that regulation the genes involved in carbohydrate metabolic and cell wall synthesis could effectively improve the high temperature, high ethanol, or high osmosis stress tolerance of $S$. cerevisiae [23, 24, 40], the specific molecular regulation mechanism of Crz1p on multiple stress-tolerance should be clarified in the future.

Those strains over-expressing ENA5 showed much better ethanol production than the original strains when fermenting different raw materials. When high-temperature SSF and VHG fermentation were carried out with pretreated straw, molasses and cassava, the concentrations of ethanol produced by the engineered strains were significantly higher than those produced by the original strains and strains reported by most researchers (Fig. 7 , Table 3) [13, 14, 41-47]. Considering the costs of materials, equipment, energy consumption and labor, the costs of ethanol production with straw, molasses and cassava are calculated to be about 0.60 US\$, 0.62 US\$, and 0.98 US\$ per liter (average price of ethanol in the market is about 0.75 US \$ per liter) [48-51]. Though the systematic assessments of changes of parameters including fermentation temperature, mash concentration, and ethanol concentration on the ethanol production cost when different feedstocks are used is needed. Several studies reported that if the fermentation temperature is increased by $1{ }^{\circ} \mathrm{C}$ and if the ethanol yield is increased by $10 \%$, the cost of ethanol can be reduced by about 0.04 US\$ per liter and 0.03 US\$ per liter, respectively $[51,52]$. This suggested that the strains engineered in the present study have good prospects for reducing ethanol production cost and hence have wide industrial applications.

In the previous study, we obtained strain E-158 using KF-7 as the original strain by combined techniques including ARTP mutagenesis, genome shuffling and hybridization, which took a lot of time and labor [18]. However, in the present study, the key gene 
Table 3 Comparisons of ethanol concentrations of strains when different raw materials were fermented under stress conditions

\begin{tabular}{|c|c|c|c|c|c|}
\hline Strains & Process (Solid content) & Temperature $\left({ }^{\circ} \mathrm{C}\right)$ & Substrates & $\begin{array}{l}\text { Ethanol } \\
\text { concentration } \\
\text { (g/L) }\end{array}$ & References \\
\hline \multicolumn{6}{|l|}{ Cellulose materials } \\
\hline S. cerevisiae Angel Yeast & P-SSF (20\%) & 39.0 & Corn stover & 59.80 & {$[41]$} \\
\hline S. cerevisiae TJ14 & P-SSF (/) & 39.0 & Microcrystalline cellulose & 45.00 & {$[42]$} \\
\hline K. marxianus NRRL Y-6860 & SSF (24\%) & 41.5 & Rice straw & 52.30 & {$[43]$} \\
\hline KF-7 & P-SSF (20\%) & 42.0 & Rice straw & 55.89 & This study \\
\hline KF-7-ENA5 & P-SSF (20\%) & 42.0 & Rice straw & 63.35 & This study \\
\hline E-158 & P-SSF (20\%) & 42.0 & Rice straw & 65.50 & This study \\
\hline E-158-ENA5 & P-SSF (20\%) & 42.0 & Rice straw & 68.40 & This study \\
\hline \multicolumn{6}{|l|}{ Molasses } \\
\hline S. cerevisiae NCYC3233-27c & $\mathrm{VHG}(/)$ & 35.0 & Unpretreated molasses & 78.90 & [14] \\
\hline S. cerevisiae UAF-1 & VHG (270.0 g/L) & 32.0 & Acid pretreated molasses & 96.00 & {$[44]$} \\
\hline S. cerevisiae SFO6 & VHG (250.0 g/L) & 30.0 & Unpretreated molasses & 55.20 & [13] \\
\hline KF-7 & VHG (270.9 g/L) & 33.0 & Unpretreated molasses & 77.20 & This study \\
\hline KF-7-ENA5 & VHG (270.9 g/L) & 33.0 & Unpretreated molasses & 94.43 & This study \\
\hline E-158 & VHG (270.9 g/L) & 33.0 & Unpretreated molasses & 95.71 & This study \\
\hline E-158-ENA5 & VHG (270.9 g/L) & 33.0 & Unpretreated molasses & 98.28 & This study \\
\hline \multicolumn{6}{|l|}{ Cassava } \\
\hline S. cerevisiae CHY1011 & SSF (18\%) & 32.0 & Cassava & 89.10 & {$[45]$} \\
\hline S. cerevisiae dry yeast & SSF (20\%) & 30.0 & Cassava & 71.84 & {$[46]$} \\
\hline S. cerevisiae G2-3-2 & SSF (23\%) & 30.0 & Cassava & 115.77 & [47] \\
\hline KF-7 & SSF (35\%) & 33.0 & Cassava & 121.34 & This study \\
\hline KF-7-ENA5 & SSF (35\%) & 33.0 & Cassava & 129.23 & This study \\
\hline E-158 & SSF (35\%) & 33.0 & Cassava & 134.70 & This study \\
\hline E-158-ENA5 & SSF (35\%) & 33.0 & Cassava & 138.43 & This study \\
\hline
\end{tabular}

ENA5 mined by a comprehensive strategy was identified to successfully enhance multiple stresses. The engineered strain obtained by overexpression of ENA5 in KF-7 had similar fermentation results to E-158 under all five stress conditions (Tables 1,2), suggesting the very high effectiveness of reverse metabolic engineering employed in the present study. Directly engineering the identified key target genes significantly reduced the time and labor. Therefore, such strategy is powerful to accumulate target gene information, which can be further adopted to support the construction of excellent industrial strains.

In addition to $E N A 5$, other genes investigated in the present study that contributed to stress tolerance phenotype can be applied to obtain strains with specific stress tolerance or multiple stress-tolerant strains by simultaneously regulating the expression of more than one of them. The effect of ENA5 and other genes on the stress tolerance phenotypes can also be explored using $S$. cerevisiae strains with different genetic backgrounds, including xylose-fermenting $S$. cerevisiae strains, and even other microorganisms having industrial application potentials.

\section{Conclusion}

In this study, six novel genes including functional genes, genes of unknown function and genes encoding TFs, were found for the first time to be related to the multiple stress-tolerant phenotypes of industrial S. cerevisiae. Overexpression of gene ENA5 significantly improved the high ethanol, high temperature, high sugar, and high salt tolerance phenotypes of the original strain KF-7 and the resistant strain E-158. The fermentation performance of the engineered strains under stress conditions was much better than strains reported by most researchers. These findings provide new insights guiding the engineering of S. cerevisiae strains towards higher ethanol production in the presence of diverse environmental stresses.

\section{Materials and methods}

Strains, plasmids, primers, and media

All the strains and plasmids used and constructed in this study were listed in Table 4 [53, 54]. A flocculating industrial S. cerevisiae strain KF-7, which has good ethanol fermentation capacity and stress tolerance, was used as the original strain $[55,56]$. The multiple 
Table 4 Plasmids and strains

\begin{tabular}{|c|c|c|}
\hline Plasmids and strains & Description & References \\
\hline \multicolumn{3}{|l|}{ Plasmids } \\
\hline Cas9-NAT & Ampr; Cas9; NAT1 & {$[53]$} \\
\hline PMEL13 & Ampr; $2 \mu$ m origin, KanMX, gRNA-CAN1.Y & {$[54]$} \\
\hline PMEL13-CRZ1 & Ampr; 2 um origin, KanMX, gRNA-CRZ1 & This study \\
\hline PMEL13-ENA5 & Ampr; 2 um origin, KanMX, gRNA-ENA5 & This study \\
\hline PMEL13-ASP3 & Ampr; $2 \mu m$ origin, KanMX, gRNA-ASP3 & This study \\
\hline PMEL13-TOS8 & Ampr; $2 \mu \mathrm{m}$ origin, KanMX, gRNA-TOS8 & This study \\
\hline PMEL13-YOL162W & Ampr; $2 \mu \mathrm{m}$ origin, KanMX, gRNA-YOL162W & This study \\
\hline PMEL13-YOR012W & Ampr; $2 \mu \mathrm{m}$ origin, KanMX, gRNA-YOR012W & This study \\
\hline \multicolumn{3}{|l|}{ Strains } \\
\hline KF-7 & Flocculating diploid industrial Saccharomyces cerevisiae strain & {$[55]$} \\
\hline $\mathrm{E}-158$ & KF-7; Random mutagenesis and hybridization & {$[18]$} \\
\hline KF-7-CRZ1 & $\mathrm{KF}-7$; Replacement of promoter $\mathrm{P}_{C R Z 1}$ to $\mathrm{P}_{\text {TEF1 }}$ & This study \\
\hline KF-7-ENA5 & $\mathrm{KF}-7$; Replacement of promoter $\mathrm{P}_{\text {ENAS }}$ to $\mathrm{P}_{\text {TEF } 1}$ & This study \\
\hline $\mathrm{KF}-7 \triangle \mathrm{ASP} 3$ & KF-7; Knockout ASP3 & This study \\
\hline KF-7 $\triangle \mathrm{TOS} 8$ & KF-7; Knockout TOS8 & This study \\
\hline KF-7 $\triangle \mathrm{YOL} 162 \mathrm{~W}$ & KF-7; Knockout YOL162W & This study \\
\hline KF-7 $\triangle \mathrm{YOR} 012 \mathrm{~W}$ & KF-7; Knockout YOR012W & This study \\
\hline E-158-CRZ1 & E-158; Replacement of promoter $\mathrm{P}_{C R Z 1}$ to $\mathrm{P}_{\text {TEF1 }}$ & This study \\
\hline E-158-ENA5 & $\mathrm{E}-158$; Replacement of promoter $\mathrm{P}_{E N A 5}$ to $\mathrm{P}_{\text {TEF } 1}$ & This study \\
\hline
\end{tabular}

stress-tolerant strain E-158 was obtained by mutagenesis and hybridization using KF-7 as the starting strain in our previous study [18]. Escherichia coli DH5 $\alpha$ was used for gene cloning and manipulation. Primers and other DNA fragments used in this study were presented in Table 5 and Additional file 1: Table S6.

YP medium (10 g/L yeast extract, $20 \mathrm{~g} / \mathrm{L}$ peptone) containing $20 \mathrm{~g} / \mathrm{L}$ glucose (YPD20) was used for cell growth. YP medium containing $150 \mathrm{~g} / \mathrm{L}$ glucose (YPD150) and 8.0\% (v/v) ethanol was used for ethanolstress fermentation. YP medium containing $100 \mathrm{~g} / \mathrm{L}$ glucose (YPD100) was used for heat-stress fermentation. YP medium containing $100 \mathrm{~g} / \mathrm{L}$ glucose (YPD100) and $2.6 \%(\mathrm{v} / \mathrm{v})$ ethanol was used for multiple-stress (ethanol and heat) fermentation. YP medium containing 270/280 g/L glucose (YPD270/280) was used for VHG-stress fermentation. YP medium containing $150 \mathrm{~g} / \mathrm{L}$ glucose (YPD150) and 1.25/1.5 mol/L NaCl was used for salt-stress fermentation. YP medium containing $20 \mathrm{~g} / \mathrm{L}$ glucose (YPD20), $20 \mathrm{~g} / \mathrm{L}$ agar, $50 \mathrm{ng} /$ $\mathrm{mL}$ nourseothricin (NAT), and $100 \mathrm{ng} / \mathrm{mL}$ geneticin (G418) was used for yeast transformation. LB medium $(5 \mathrm{~g} / \mathrm{L}$ yeast extract, $10 \mathrm{~g} / \mathrm{L}$ peptone, and $10 \mathrm{~g} / \mathrm{L}$ $\mathrm{NaCl})$ supplemented with ampicillin $(100 \mathrm{ng} / \mathrm{mL})$ or kanamycin $(100 \mathrm{ng} / \mathrm{mL})$ was used for E. coli DH5 $\alpha$ transformation.

\section{Batch fermentations and RNA extraction}

The media and methods of batch fermentations under five stress conditions: (1) $8.0 \%$ initial ethanol; (2) $44{ }^{\circ} \mathrm{C}$; (3) $43{ }^{\circ} \mathrm{C}$ with $2.6 \%$ initial ethanol; (4) YPD270; (5) $1.25 \mathrm{M}$ $\mathrm{NaCl}$ were described in our previous study [18]. Strains were pre-cultivated in $100 \mathrm{~mL}$ YPD50 for $16 \mathrm{~h}(500 \mathrm{~mL}$ flasks). The cells were then collected, washed, and inoculated into fermentation media ( $100 \mathrm{~mL}$ in $300 \mathrm{~mL}$ flasks) with an initial cell density of $\mathrm{OD}_{660} 1.45-1.50$. The flasks were incubated in thermostatic water bath, and the media was stirred $(200 \mathrm{rpm} / \mathrm{min})$ using magnetic stirrers. Broth samples were collected during fermentation and used for the analysis of the concentrations of glucose and ethanol. For each group, three replicated fermentation experiments were independently performed for the measurements.

To prepare RNA samples for transcriptomic sequencing, cells of E-158 and KF-7 were allowed to grow till logarithmic growth under five stress conditions: (1) $8.0 \%$ initial ethanol (48 h), (2) $44{ }^{\circ} \mathrm{C}(16 \mathrm{~h}),(3) 43^{\circ} \mathrm{C}$ with $2.6 \%$ initial ethanol (12 h), (4) YPD270 (30 h), (5) $1.25 \mathrm{M} \mathrm{NaCl}$ $(48 \mathrm{~h})$. Then the cells were collected by centrifugation at $8000 \times g$ for $2 \mathrm{~min}$. Total RNA was extracted from using Yeast RNA Kit (Omega Bio-Tek, USA). For each group, three replicated fermentation experiments were independently performed. 
Table 5 Target sequences used in yeast transformation

\begin{tabular}{|c|c|c|}
\hline \multicolumn{2}{|l|}{ Target } & Sequence \\
\hline \multicolumn{3}{|l|}{ gRNA insert } \\
\hline \multicolumn{2}{|l|}{$\operatorname{tg} R-F$} & $\begin{array}{l}\text { TGCGCATGTTTCGGCGTTCGAAACTTCTCCGCAGTGAAAGA } \\
\text { TAAATGATC }\end{array}$ \\
\hline \multicolumn{2}{|l|}{$\operatorname{tg} R-R$} & $\begin{array}{l}\text { GTTGATAACGGACTAGCCTTATTTTAACTTGCTATTTCTAGC } \\
\text { TCTAAAAC }\end{array}$ \\
\hline ENA5 & CS & GATAACGTATGTACTCACTGAGG \\
\hline CRZ1 & CS & GCAGAATGTCTACTACGTCGAGG \\
\hline ASP3 & CS & GCTACGGCATGGATCAGATTAGG \\
\hline TOS8 & CS & AGAAATTACATAATAACTGTAGG \\
\hline YOL162W & CS & AAGGTACAATGTTTAATAAATGG \\
\hline YOR012W & CS & TTGAAACTTTTTCAGTGATTGGG \\
\hline \multicolumn{3}{|c|}{ Repair fragment } \\
\hline \multirow[t]{2}{*}{ TEF1 } & $\mathrm{F}$ & CACACACCATAGCTTCAAAATG \\
\hline & $\mathrm{R}$ & TTTGTAATTAAAACT \\
\hline \multirow[t]{4}{*}{ ENA5 } & RF F & СCTTCATCCTTTACATCGAGAATACGTTAACCAAATCAACCACACACCATAGCTTCAAAATG \\
\hline & RFR & ATTCTTCATTATTGTTTTCTTTGACAGTTCCCTCGCTCATTTTGTAATTAAAACT \\
\hline & $V_{p} F$ & TTGTGAGGCTGATGTTTTCTTC \\
\hline & $V_{p} R$ & GCTTCTTCTGTAGTCAATGTGTGAT \\
\hline \multirow[t]{4}{*}{ CRZ1 } & RF F & GGGCTGAAAAGTACATCCGCGCATTTAACAATTGCTAAGCCACACACCATAGCTTCAAAATG \\
\hline & RF R & TAGTCATGTAGGAAGCCATATTTCCGTTGCTGAATGACATTTTGTAATTAAAACT \\
\hline & $V_{p} F$ & GCTTTGACTGCACTTTAGCTTAG \\
\hline & $V_{p} R$ & TTTCCGTTGCTGAATGACAT \\
\hline \multirow[t]{4}{*}{ ASP3 } & RF F & $\begin{array}{l}\text { AGAGCAAATGTTGGCTCGCTATTCTTTTGTAAGCAATCTGGTACTCACCAACCTCCAACTAGCCTGATCAGTGACTTTTCATCACACTGT } \\
\text { GTTTTTATATAGTTCTTAGTAGTAAATATA }\end{array}$ \\
\hline & RF R & $\begin{array}{l}\text { TATATTTACTACTAAGAACTATATAAAAACACAGTGTGATGAAAAGTCACTGATCAGGCTAGTTGGAGGTTGGTGAGTACCAGATTGCTTACA } \\
\text { AAAGAATAGCGAGCCAACATTTGCTCT }\end{array}$ \\
\hline & $V_{p} F$ & TATCAGACCCTTCAGCACGT \\
\hline & $V_{p} R$ & TGACACTGCTCAAGGGATAA \\
\hline \multirow[t]{4}{*}{ TOS8 } & RF F & $\begin{array}{l}\text { TTTTTCAGTATAGGAAGTAATCACTGTAGAAATAAGTCAACAATAATTGCATAGAAAAAATTTTACTTTTTTCGGAATTACCTAAAATGGGTT } \\
\text { TACGGCATAGAAGATAGATAGATTAAG }\end{array}$ \\
\hline & RF R & $\begin{array}{l}\text { CTTAATCTATCTATCTTCTATGCCGTAAACCCATTTTAGGTAATTCCGAAAAAAGTAAAATTTTTTCTTATGCAATTATTGTTGACTTATTTCTACA } \\
\text { GTGATTACTTCCTATACTGAAAAA }\end{array}$ \\
\hline & $V_{p} F$ & GTTCCCTTGTTTTGAAGCAC \\
\hline & $V_{p} R$ & CGAAGATTCTCACCAAAGTT \\
\hline \multirow[t]{4}{*}{ YOL162W } & RF F & $\begin{array}{l}\text { ATGTCACTTAAAATGTTATGGCAGGGGATAACAGATTACTATATATAGCCTATCTACTTGACTATGTAGAAATATGGATACAATCTCCATGTT } \\
\text { ATGTATTTTTTAAGTTTGTGAATCATT }\end{array}$ \\
\hline & RF R & $\begin{array}{l}\text { AATGATTCACAAACTTAAAAAATACATAACATGGAGATTGTATCCATATTTCTACATAGTCAAGTAGATAGGCTATATATAGTAATCTGTTATCCC } \\
\text { CTGCCATAACATTTTAAGTGACAT }\end{array}$ \\
\hline & $V_{p} F$ & CTAAGCAATCACCTAAACAT \\
\hline & $V_{p} R$ & GATGTCGTACTTCTACAGCT \\
\hline \multirow[t]{4}{*}{ YORO12W } & RF F & $\begin{array}{l}\text { GAAAAAGGCAGTGACAAAAATACTAATCAGAACGTTGAAAACAAATCAATAGTTTTGATACCATCCCGAAATTAGAGGTTCAGTCAGAAA } \\
\text { AATACTCGAAAAATATAAAACCAAAGCAGA }\end{array}$ \\
\hline & RF R & $\begin{array}{l}\text { TCTGCTTTGGTTTTATATTTTTCGAGTATTTTTCTGACTGAACCTCTAATTTCGGGATGGTATCAAAACTATTGATTTGTTTTCAACGTTCTG } \\
\text { ATTAGTATTTTTGGTCACTGCCTTTTTC }\end{array}$ \\
\hline & $V_{p} F$ & TGCCTCATAACGTCTTGGGG \\
\hline & $V_{p} R$ & GTAGGCCGTGAATCCCTTCC \\
\hline
\end{tabular}

$\operatorname{tg} R-F$ : upstream homologous of gRNA; tgR-R: downstream homologous of gRNA; CS: complementary sequence; RF: repair fragment; Vp: verification primer; F: forward primer; R: reverse primer, "double underline" represent the PAM (NGG) site, "underline" represent homologous arm

\section{Transcriptomic data analysis}

A total of 30 mRNA samples (KF-7 and E-158 each had three parallel samples under each stress condition) were sequenced using an Illumina Novaseq 6000 platform (Shanghai Majorbio Biopharm Technology Co. Ltd. (Shanghai, China)). Library construction was conducted 
using the Illumina Truseq ${ }^{\mathrm{TM}}$ RNA sample prep kit. The mRNA was separated from total RNA by A-T base pairing, and then was broken into small fragments of about 300 bp by the addition of fragmentation buffer. The cDNA was synthesized using mRNA as the template. The sticky ends of the double-stranded cDNA were bluntended with End Repair Mix, then an A-base was added to the $3^{\prime}$ end for the linker to the Y-line. The resulting fragments were subjected to Illumina Novaseq sequencing. The Clean Data of each sample reached more than $6.32 \mathrm{~Gb}$.

Difference in gene expression levels of one gene between KF-7 and E-158 was quantified by an index, $\log _{2} \mathrm{FC}$, representing the logarithm to base 2 of the ratio of the RNA reads number of the gene in E158 to that in KF7. If $\left|\log _{2} \mathrm{FC}\right| \geq 1$ and $P<0.05$, the expression of the related gene was defined to significantly change. These analyses were performed on the online platform called Majorbio Cloud Platform (www.majorbio.com). The shared DEGs under five stress conditions were visualized by Venn-diagram (http://jvenn.toulouse.inra.fr/app/ example.html). Gene Ontology (GO) enrichment of the shared DEGs was carried out with online tools developed by Princeton University (http://go.princeton.edu/cgi-bin/ GOTermMapper), in which $P \leq 0.001$ and enrichment ratio $\geq 0.1$ was set as the threshold. Kyoto Encyclopedia of Genes and Genomes (KEGG) enrichment analysis of the shared DEGs was performed using the KEGG database (http://www.genome.jp/kegg/). The threshold was set to $P \leq 0.05$ and enrichment ratio $\geq 0.1$. The shared DEGs were searched in the YEASTRACT database (http://www.yeastract.com/formfindregulators.php) to find the potential TFs. The protein-protein interaction network of shared DEGs was analyzed and constructed using Cytoscape 3.7.2 software. The original sequencing data are accessed in the National Center for Biotechnology Information platform under accession number PRJNA642097.

\section{Strains construction}

CRISPR/Case9 gene-editing technology was used to over express or knock out the genes, and the experiments were performed according to $\mathrm{Li}$ et al. [37]. For gRNA plasmid construction, the linearized plasmid backbone and gRNA insertion fragments were assembled to form the guideRNA (gRNA) plasmid. The linearized plasmid backbone was PCR amplified from pMEL13 plasmid using primer 6005/6006 [54]. The gRNA insert (120 bp) was composed of upstream homologous arm (tgR-F, $50 \mathrm{bp}$ ), downstream homologous arm (tgR-R, $50 \mathrm{bp}$ ), and complementary sequence $(20 \mathrm{bp})$. The sequences were synthesized in GENEWIZ (Suzhou, China). The complementary sequence of gRNA was located in the promoter region for overexpression of gene CRZ1 or ENA5 (Additional file 1: Fig. S2A), and the complementary sequences of gRNA were located in the coding sequence (CDS) region for knocking out genes $A S P 3, T O S 8, Y O L 162 \mathrm{~W}$, or $Y O R 012 W$ (Additional file 1: Fig. S2B). The gRNA sequences were designed using the E-CRISP tool at http://www.e-crisp.org/E-CRISP/ (Table 5). The gRNA was integrated into the linearized backbone using Gibson assembly according to the manufacture's manual of Gibson Assembly ${ }^{\circledR}$ Master Mix (New England Biolabs, Beverly, MA, USA). Each plasmid was transformed into E. coli DH5 $\alpha$. After sequencing, the plasmids containing correct inserts were subsequently used for transformation.

The strength of the promoter TEF1 ( $\left.\mathrm{P}_{T E F 1}, 420 \mathrm{bp}\right)$ was high and relatively stable under five stress conditions (Additional file 1: Table S7). $\mathrm{P}_{T E F 1}$ was used to replace the promoters of CRZ1 and ENA5. The repair fragment was amplified using KF-7 genome as template, and it contained upstream homologous arm, downstream homologous arm, and TEF1 sequence (Additional file 1: Fig. S2A). The repair fragments of ASP3, TOS8, YOL162W, and $Y O R 012 W$ were composed of upstream arm (60 bp) and downstream arm $(60 \mathrm{bp})$ of the target gene CDS, which were synthesized in GENEWIZ (Suzhou, China) (Table 5, Additional file 1: Fig. S2B).

For yeast transformation, the lithium acetate method was used according to the protocol proposed by Finlayson et al. [57]. Cas9 plasmid was first transformed into KF-7 and E-158. The gRNA plasmid and repair fragment $\left(\mathrm{P}_{T E F 1}\right)$ were then transformed into the strains harboring Cas9 plasmid. Transformants grown on 2\% YPD plate containing $0.005 \%$ NAT and $0.01 \%$ G418 were confirmed by PCR and Sanger sequencing. The removement of Cas9 and gRNA plasmids from the transformants were conducted according to Mans' method [54]. The transformants were subjected to the following fermentation evaluation.

\section{Evaluation of growth and fermentation performance of engineered strains}

The growth of engineered strains under different stress conditions was evaluated using YPD20 agar medium. The engineered strains were pre-cultivated in YPD50 medium for $16 \mathrm{~h}$ to logarithmic growth phase, and the cells were harvested by centrifugation at $8000 \times g$ for $2 \mathrm{~min}$ at $4{ }^{\circ} \mathrm{C}$. The cells were washed twice using sterilized water and re-suspended in sterilized $0.5 \mathrm{~mol} / \mathrm{L}$ ethylenediaminetetraacetic acid disodium salt (EDTA$2 \mathrm{Na}$ ) solution with a final $\mathrm{OD}_{660}$ of 1.0 . The solution was then serially tenfold diluted. Aliquots of $2 \mu \mathrm{L}$ were spotted on YPD20 agar medium containing 13\% (v/v) ethanol, $400 \mathrm{~g} / \mathrm{L}$ glucose, $3 \mathrm{~mol} / \mathrm{L}$ sorbitol, and $2 \mathrm{~mol} / \mathrm{L}$ 
$\mathrm{NaCl}$. The plates were incubated at $30{ }^{\circ} \mathrm{C}$ for $72-120 \mathrm{~h}$. To examine the growth at high temperature, the plates were incubated at $44{ }^{\circ} \mathrm{C}$ for $72 \mathrm{~h}$.

The fermentation capacity under different stress conditions was evaluated using both YPD medium and three different raw materials. The method of fermentation using YPD medium was the same as described in Batch fermentation and RNA extraction. The compositions of the pretreated straw, molasses, and cassava used in fermentation were shown in Additional file 1: Tables S2, S3 and S4. The fermentation using the pretreated straw was performed by pre-saccharification and SSF at $42{ }^{\circ} \mathrm{C}$. The solid content of pretreated straw was adjusted to $20 \%$ with PBS buffer solution ( $\mathrm{pH} 5$ ). $\mathrm{CTec} 3$ was added at a dosage of $20 \mathrm{FPU} / \mathrm{g}$ cellulose. The slurry was pre-saccharified for $8 \mathrm{~h}$ at $50{ }^{\circ} \mathrm{C}$. The presaccharified slurry was inoculated with pre-cultivated fresh cells ( $0.5 \mathrm{~g}$ dry weight $/ \mathrm{kg}$ slurry), and the SSF was conducted in a thermostat water bath for $96 \mathrm{~h}$ at $42{ }^{\circ} \mathrm{C}$. The VHG fermentation using molasses was conducted at $33{ }^{\circ} \mathrm{C}$. Diluted molasses (total sugar concentration of $270.91 \mathrm{~g} / \mathrm{L}$ ) was inoculated with pre-cultivated fresh cells $(0.5 \mathrm{~g}$ dry weight/L), and the VHG fermentation was conducted in a thermostat water bath for $96 \mathrm{~h}$ at $33{ }^{\circ} \mathrm{C}$. High solid SSF of cassava was performed at $33{ }^{\circ} \mathrm{C}$. Cassava slurry with $35 \%$ solid content was gelatinized at $105^{\circ} \mathrm{C}$ for $15 \mathrm{~min}$. The resultant gelatinized slurry was liquefied at $95{ }^{\circ} \mathrm{C}$ for $2 \mathrm{~h}$ by $\alpha$-amylase $(10$ $\mathrm{U} / \mathrm{g}$ starch). After cooling to room temperature, glucoamylase $(160 \mathrm{U} / \mathrm{g}$ starch), pectinase $(20 \mathrm{U} / \mathrm{g}$ raw materials), cellulase $\left(10 \mathrm{U} / \mathrm{g}\right.$ raw materials), $1 \mathrm{~g} / \mathrm{L} \mathrm{KH}_{2} \mathrm{PO}_{4}$, $0.5 \mathrm{~g} / \mathrm{L} \mathrm{CaCl}_{2} \mathrm{H}_{2} \mathrm{O}, 0.5 \mathrm{~g} / \mathrm{L} \mathrm{MgSO}_{4} .7 \mathrm{H}_{2} \mathrm{O}$, and $1 \mathrm{~g} / \mathrm{L}$ $\left(\mathrm{NH}_{2}\right)_{2} \mathrm{CO}$ were added. Pre-cultivated fresh cells $(0.5 \mathrm{~g}$ dry weight $/ \mathrm{kg}$ slurry) were inoculated. SSF was conducted in a thermostat water bath for $96 \mathrm{~h}$ at $33{ }^{\circ} \mathrm{C}$. All fermentation experiments were performed three times independently.

\section{Analytical methods}

Broth samples were diluted and filtered through $0.22 \mu \mathrm{m}$ filters before analysis. The concentration of glucose was determined by HPLC (LC-10 ADVP, Shimadzu, Kyoto, Japan) at $25^{\circ} \mathrm{C}$, with a mobile phase of $5 \mathrm{mmol} / \mathrm{L}$ sulfuric acid at a flow rate of $0.6 \mathrm{~mL} / \mathrm{min}$. Ethanol concentration was determined using gas chromatography (GC 353B, GL Sciences, Kyoto, Japan) with an FID detector, and isopropanol was used as the internal standard. The data were expressed as the means with standard deviations. Variance analysis was conducted using Tukey-test with SPSS statistical package (SPSS Inc., Chicago, IL, USA). The level of statistical significance was set at $P<0.05$.

\section{Supplementary Information}

The online version contains supplementary material available at https://doi. org/10.1186/s13068-022-02109-x.

Additional file 1. Additional Figures and Tables.

Acknowledgements

Not applicable.

\section{Authors' contributions}

LW: conceptualization, methodology, investigation, validation, and writingoriginal draft. BL: formal analysis and methodology. RS: formal analysis. SW: investigation and methodology. ZX: writing-review and editing. CX: supervision and software. YT: conceptualization, writing-review \& editing, data curation, supervision and funding acquisition. All authors read and approved the final manuscript.

\section{Funding}

This work was supported by National Key R\&D Program of China (2018YFA0902100 and 2018YFA0902102).

\section{Availability of data and materials}

The datasets used and/or analyzed during the current study are available from the corresponding author on reasonable request. The original RNA sequencing data can be accessed through the National Center for Biotechnology Information (https://www.ncbi.nlm.nih.gov/) under project accession no. PRJNA642097.

\section{Declarations}

Ethics approval and consent to participate

Not applicable.

\section{Consent for publication}

All the authors agreed for publication.

\section{Competing interests}

The authors declare that they have no competing interests.

\section{Author details}

${ }^{1}$ College of Architecture and Environment, Sichuan University, No. 24 South Section 1 First Ring Road, Chengdu 610065, Sichuan, China. ${ }^{2}$ Institute of New Energy and Low-Carbon Technology, Sichuan University, No. 24 South Section 1 First Ring Road, Chengdu 610065, Sichuan, China. ${ }^{3}$ Engineering Research Center of Alternative Energy Materials \& Devices, Ministry of Education, China, No. 24 South Section 1 First Ring Road, Chengdu 610065, Sichuan, China. ${ }^{4}$ Sichuan Environmental Protection Key Laboratory of Organic Wastes Valorization, No. 24 South Section 1 First Ring Road, Chengdu 610065, Sichuan, China.

Received: 13 November 2021 Accepted: 9 January 2022

Published online: 21 January 2022

\section{References}

1. Favaro L, Jansen T, van Zyl WH. Exploring industrial and natural Saccharomyces cerevisiae strains for the bio-based economy from biomass: the case of bioethanol. Crit Rev Biotechnol. 2019;39(6):800-16. https://doi. org/10.1080/07388551.2019.1619157.

2. Mat Aron NS, Khoo KS, Chew KW, Show PL, Chen WH, Nguyen THP. Sustainability of the four generations of biofuels - a review. Int J Energy Res. 2020;44(12):9266-82. https://doi.org/10.1002/er.5557.

3. Ha-Tran DM, Nguyen TTM, Huang CC. Kluyveromyces marxianus: current state of omics studies, strain improvement strategy and potential industrial implementation. Fermentation. 2020;6:124. https://doi.org/10.3390/ fermentation6040124. 
4. Xia J, Yang YF, Liu CG, Yang SH, Bai FW. Engineering Zymomonas mobilis for robust cellulosic ethanol production. Trends Biotechnol. 2019;37(9):960-72. https://doi.org/10.1016/j.tibtech.2019.02.002.

5. Nosrati-Ghods N, Harrison STL, Isafiade AJ, Taia SL. Analysis of ethanol production from xylose using Pichia stipitis in microaerobic conditions through experimental observations and kinetic modelling. Biochem Eng J. 2020;164: 107754. https://doi.org/10.1016/j.bej.2020.107754.

6. Benjamin B, Bakare DV, Effiong TE. Saccharomyces cerevisiae bio-ethanol production as an alternative source of sustainable energy ethanol production using Saccharomyces cerevisiae. Int J Res Appl Sci Biotechnol. 2020;7(6):190-4. https://doi.org/10.31033/ijrasb.7.6.27.

7. Akhtar N, Karnwal A, Upadhyay AK, Paul S, Mannan MA. Saccharomyces cerevisiae bio-ethanol production, a sustainable energy alternative. Asian J Microbiol Biotechnol Environ Sci. 2018;20:S202-6.

8. Jhariya U, Dafale NA, Srivastava S, Bhende RS, Kapley A, Purohit HJ. Understanding ethanol tolerance mechanism in Saccharomyces cerevisiae to enhance the bioethanol production: current and future prospects. BioEnergy Res. 2021;14:670-88. https://doi.org/10.1007/s12155-020-10228-2.

9. Khatun MM, Yu XS, Kondo A, Bai FW, Zhao XQ. Improved ethanol production at high temperature by consolidated bioprocessing using Saccharomyces cerevisiae strain engineered with artificial zinc finger protein. Bioresour Technol. 2017;245:1447-54. https://doi.org/10.1016/j.biortech. 2017.05.088.

10. Nogueira CD, Padilha CED, dos Santos ES. Enzymatic hydrolysis and simultaneous saccharification and fermentation of green coconut fiber under high concentrations of ethylene oxide-based polymers. Renew Energ. 2021:163:1536-47. https://doi.org/10.1016/j.renene.2020.10.050.

11. Wu YD, Wang ZZ, Ma X, Xue C. High temperature simultaneous saccharification and fermentation of corn stover for efficient butanol production by a thermotolerant Clostridium acetobutylicum. Process Biochem. 2021:100:20-5. https://doi.org/10.1016/.jprocbio.2020.09.026.

12. Liu JJ, Ding WT, Zhang GC, Wang JY. Improving ethanol fermentation performance of Saccharomyces cerevisiae in very high-gravity fermentation through chemical mutagenesis and meiotic recombination. Appl Microbiol Biotechnol. 2011;91(4):1239-46. https://doi.org/10.1007/ s00253-011-3404-2.

13. Faramarzi S, Anzabi Y, Jafarizadeh-Malmiri H. Selenium supplementation during fermentation with sugar beet molasses and Saccharomyces cerevisiae to increase bioethanol production. Green Process Synth. 2019;8(1):622-8. https://doi.org/10.1515/gps-2019-0032.

14. Inai T, Watanabe D, Zhou Y, Fukada R, Akao T, Shima J, Takagi H, Shimoi H. Rim 15p-mediated regulation of sucrose utilization during molasses fermentation using Saccharomyces cerevisiae strain PE-2. J Biosci Bioeng. 2013;116(5):591-4. https://doi.org/10.1016/j.jbiosc.2013.05.015.

15. Chen $Y H$, Zhang $X$, Zhang M, Zhu JY, Wu ZF, Zheng XJ. A transcriptome analysis of the ameliorate effect of Cyclocarya paliurus triterpenoids on ethanol stress in Saccharomyces cerevisiae. World J Microbiol Biotechnol. 2018;34(12):182. https://doi.org/10.1007/s11274-018-2561-1.

16. Xu K, Yu LP, Bai WX, Xiao B, Liu YQ, Lv B, Li J, Li C. Construction of thermotolerant yeast based on an artificial protein quality control system (APQC) to improve the production of bio-ethanol. Chem Eng Sci. 2018;177:4106. https://doi.org/10.1016/j.ces.2017.12.009.

17. Qin L, Dong SX, Yu J, Ning XY, Xu K, Zhang SJ, Xu L, Li BZ, Li J, Yuan YJ, Li C. Stress-driven dynamic regulation of multiple tolerance genes improves robustness and productive capacity of Saccharomyces cerevisiae in industrial lignocellulose fermentation. Metab Eng. 2020;61:160-70. https://doi. org/10.1016/j.ymben.2020.06.003.

18. Wang L, Li B, Wang SP, Xia ZY, Gou M, Tang YQ. Improving multiple stresstolerance of a flocculating industrial Saccharomyces cerevisiae strain by random mutagenesis and hybridization. Process Biochem. 2021;102:27585. https://doi.org/10.1016/j.procbio.2020.12.022.

19. Zheng DQ, Wu XC, Tao XL, Wang PM, Li P, Chi XQ, Li YD, Yan QF, Zhao $\mathrm{YH}$. Screening and construction of Saccharomyces cerevisiae strains with improved multi-tolerance and bioethanol fermentation performance. Bioresour Technol. 2011;102(3):3020-7. https://doi.org/10.1016/j.biortech. 2010.09.122.

20. Takagi H. Molecular mechanisms and highly functional development for stress tolerance of the yeast Saccharomyces cerevisiae. Biosci Biotech Bioch. 2021;85(5):1017-37. https://doi.org/10.1093/bbb/zbab022.

21. Diniz RHS, Villada JC, Alvim MCT, Vidigal PMP, Vieira NM, Lamas-Maceiras M, Cerdan ME, Gonzalez-Siso MI, Lahtvee PJ, da Silveira WB. Transcriptome analysis of the thermotolerant yeast Kluyveromyces marxianus CCT 7735 under ethanol stress. Appl Microbiol Biotechnol. 2017;101(18):6969-80. https://doi.org/10.1007/s00253-017-8432-0.

22. Saini P, Beniwal A, Kokkiligadda A, Vij S. Response and tolerance of yeast to changing environmental stress during ethanol fermentation. Process Biochem. 2018;72:1-12. https://doi.org/10.1016/j.procbio.2018.07.001.

23. Martinez-Alcántar L, Madrigal A, Sanchez-Briones L, Diaz-Perez AL, Lopez-Bucio JS, Campos-Garcia J. Over-expression of Isu1p and Jac1p increases the ethanol tolerance and yield by superoxide and iron homeostasis mechanism in an engineered Saccharomyces cerevisiae yeast. J Ind Microbiol Biotechnol. 2019;46(7):925-36. https://doi.org/10.1007/ s10295-019-02175-5.

24. Li PS, Fu XF, Zhang L, Zhang ZY, Li JH, Li SZ. The transcription factors Hsf1 and Msn2 of thermotolerant Kluyveromyces marxianus promote cell growth and ethanol fermentation of Saccharomyces cerevisiae at high temperatures. Biotechnol Biofuels. 2017;10:289. https://doi.org/10.1186/ s13068-017-0984-9.

25. Yin NN, Zhu GX, Luo QL, Liu J, Chen XL, Liu LM. Engineering of membrane phospholipid component enhances salt stress tolerance in Saccharomyces cerevisiae. Biotechnol Bioeng. 2020;117(3):710-20. https://doi.org/10. 1002/bit.27244

26. Benito B, Garciadeblas B, Rodri G-N. Potassium- or sodium-efflux ATPase, a key enzyme in the evolution of fungi. Microbiology. 2002;148:933-41. https://doi.org/10.1099/00221287-148-4-933.

27. Hasunuma T, Sakamoto T, Kondo A. Inverse metabolic engineering based on transient acclimation of yeast improves acid-containing xylose fermentation and tolerance to formic and acetic acids. Appl Microbiol Biotechnol. 2016;100(2):1027-38. https://doi.org/10.1007/ s00253-015-7094-z.

28. Holt S, Kankipati H, De Graeve S, Van Zeebroeck G, Foulquie-Moreno MR, Lindgreen S, Thevelein JM. Major sulfonate transporter Soa1 in Saccharomyces cerevisiae and considerable substrate diversity in its fungal family. Nat Commun. 2017:8:14247. https://doi.org/10.1038/ncomms14247.

29. Son H, Park AR, Lim JY, Lee YW. Fss1 is involved in the regulation of an ENA5 homologue for sodium and lithium tolerance in Fusarium graminearum. Environ Microbiol. 2015;17(6):2048-63. https://doi.org/10.1111/ 1462-2920.12757

30. Platara M, Ruiz A, Serrano R, Palomino A, Moreno F, Arino J. The transcriptional response of the yeast $\mathrm{Na}^{+}$-ATPase ENA1 gene to alkaline stress involves three main signaling pathways. J Biol Chem. 2006;281(48):36632-42. https://doi.org/10.1074/jbc.M606483200.

31. Oba T, Suenaga H, Muta S, Tashiro K, Kuhara S. Properties of a sucrose-tolerant mutant of Saccharomyces cerevisiae. World J Microbiol Biotechnol. 2008;24:1233-8. https://doi.org/10.1007/s11274-007-9576-3.

32. League GP, Slot JC, Rokas A. The ASP3 locus in Saccharomyces cerevisiae originated by horizontal gene transfer from Wickerhamomyces. FEMS Yeast Res. 2012;12(7):859-63. https://doi.org/10.1111/j.1567-1364.2012. 00828.x.

33. Oliveira EMM, Martins AS, Carvajal E, Bon EPS. The role of the GATA factors GIn3p, Nil1 p, Dal80p and the Ure2p on ASP3 regulation in Saccharomyces cerevisiae. Yeast. 2003;20(1):31-7. https://doi.org/10.1002/yea.930.

34. Liu H, Marsafari M, Deng L, Xu P. Understanding lipogenesis by dynamically profiling transcriptional activity of lipogenic promoters in Yarrowia lipolytica. Appl Microbiol Biotechnol. 2019;103(7):3167-79. https://doi. org/10.1007/s00253-019-09664-8.

35. Koch M, Doello S, Gutekunst K, Forchhammer K. PHB is produced from glycogen turn-over during nitrogen starvation in Synechocystis sp. PCC 6803. Int J Mol Sci. 2019;20(8):1942. https://doi.org/10.3390/ijms200819 42.

36. Li B, Xie CY, Yang BX, Gou M, Xia ZY, Sun ZY, Tang YQ. The response mechanisms of industrial Saccharomyces cerevisiae to acetic acid and formic acid during mixed glucose and xylose fermentation. Process Biochem. 2020;91:319-29. https://doi.org/10.1016/j.procbio.2020.01.002.

37. Li B, Wang L, Wu YJ, Xia ZY, Yang BX, Tang YQ. Improving acetic acid and furfural resistance of xylose-fermenting Saccharomyces cerevisiae strains by regulating novel transcription factors revealed via comparative transcriptomic analysis. Appl Environ Microbiol. 2021;87(10):e00158-e1121. https://doi.org/10.1128/AEM.00158-21.

38. Byrne KP, Wolfe KH. The yeast gene order browser: combining curated homology and syntenic context reveals gene fate in polyploid species. Genome Res. 2005;15(10):1456-61. https://doi.org/10.1101/gr.3672305. 
39. Panadero J, Hernandez-Lopez MJ, Prieto JA, Randez-Gil F. Overexpression of the calcineurin target $C R Z 1$ provides freeze tolerance and enhances the fermentative capacity of baker's yeast. Appl Environ Microbiol. 2007;73(15):4824-31. https://doi.org/10.1128/AEM.02651-06.

40. Chen Y, Lu ZL, Chen D, Wei YT, Chen XL, Huang J, Guan N, Lu Q, Wu RZ, Huang R. Transcriptomic analysis and driver mutant prioritization for differentially expressed genes from a Saccharomyces cerevisiae strain with high glucose tolerance generated by UV irradiation. RSC Adv. 2017:7:38784-97. https://doi.org/10.1039/c7ra06146c.

41. Liu ZH, Qin L, Zhu JQ, Li BZ, Yuan YJ. Simultaneous saccharification and fermentation of steam-exploded corn stover at high glucan loading and high temperature. Biotechnol Biofuels. 2014;7:167-83. https://doi.org/10. 1186/s13068-014-0167-x.

42. Shahsavarani H, Hasegawa D, Yokota D, Sugiyama M, Kaneko Y, Boonchird C, Harashima S. Enhanced bio-ethanol production from cellulosic materials by semi-simultaneous saccharification and fermentation using high temperature resistant Saccharomyces cerevisiae TJ14. J Biosci Bioeng. 2013;115(1):20-3. https://doi.org/10.1016/j.jbiosc.2012.07.018.

43. Roberto IC, Castro RCA, Silva JPA, Mussatto SI. Ethanol production from high solid loading of rice straw by simultaneous saccharification and fermentation in a non-conventional reactor. Energies. 2020;13(8):1-17. https://doi.org/10.3390/en13082090.

44. Arshad M, Hussain T, lqbal M, Abbas M. Enhanced ethanol production at commercial scale from molasses using high gravity technology by mutant S. cerevisiae. Braz J Microbiol. 2017;48(3):403-9. https://doi.org/10. 1016/j.bjm.2017.02.003.

45. Choi G-W, Um H-J, Kim Y, Kang HW, Kim M, Chung BW, Kim YH. Isolation and characterization of two soil derived yeasts for bioethanol production on cassava starch. Biomass Bioenergy. 2010;34(8):1223-31. https://doi. org/10.1016/j.biombioe.2010.03.019.

46. Jos B, Kumoro AC. Production of bioethanol from sweet and bitter cassava starches by simultaneous saccharification and fermentation using Saccharomyces cerevisiae. Adv Sci Lett. 2017;23(3):2427-31. https://doi. org/10.1166/asl.2017.8682.

47. Palasak T, Sooksai S, Savarajara A. Comparison of yeast extract prepared by autolysis or steam explosion as a cheap nutrient supplement for very high gravity ethanol fermentation of cassava starch. ScienceAsia. 2019;45(1):3-9. https://doi.org/10.2306/scienceasia1513-1874.2019.45. 003.

48. Ranganathan P. Preliminary techno-economic evaluation of $2 \mathrm{G}$ ethano production with co-products from rice straw. Biomass Convers Biorefin. 2020. https://doi.org/10.1007/s13399-020-01144-8.

49. Aui A, Wang Y, Mba-Wright M. Evaluating the economic feasibility of cellulosic ethanol: a meta-analysis of techno-economic analysis studies. Renew Sustain Energy Rev. 2021;145: 111098. https://doi.org/10.1016/j. rser.2021.111098.

50. Arshad M, Abbas M, lqbal M. Ethanol production from molasses: environmental and socioeconomic prospects in Pakistan: feasibility and economic analysis. Environ Technol Innovation. 2019;14: 100317. https:// doi.org/10.1016/j.eti.2019.100317.

51. Quintero JA, Cardona CA, Felix E, Moncada J, Higuita JC. Techno-economic analysis of fuel ethanol production from cassava in Africa: the case of Tanzania. Afr J Biotechnol. 2015;14(45):3082-92. https://doi.org/10. 5897/AJB2013.13239.

52. Tao L, Schell D, Davis R, Tan E, Elander R, Bratis A. NREL 2012 achievement of ethanol cost targets: biochemical ethanol fermentation via dilute-acid pretreatment and enzymatic hydrolysis of corn stover. Inorganic organic physical \& analytical chemistry. 2014; NREL/TP-5100-61563. https://doi. org/10.2172/1129271

53. Zhang GC, Kong II, Kim H, Liu JJ, Cate JHD, Jin YS. Construction of a quadruple auxotrophic mutant of an industrial polyploid Saccharomyces cerevisiae strain by using RNA-Guided Cas9 nuclease. Appl Environ Microbiol. 2014;80:7694-701. https://doi.org/10.1128/AEM.02310-14.

54. Mans R, van Rossum HM, Wijsman M, Backx A, Kuijpers NG, van den Broek M, Daran-Lapujade P, Pronk JT, van Maris AJ, Daran JM. CRISPR/Cas9: a molecular Swiss army knife for simultaneous introduction of multiple genetic modifications in Saccharomyces cerevisiae. FEMS Yeast Res. 2015;15:1-15. https://doi.org/10.1093/femsyr/fov004.

55. Kida K, Kume K, Morimura S, Sonoda Y. Repeated-batch fermentation process using a thermotolerant flocculating yeast constructed by protoplast fusion. J Ferment Bioeng. 1992;74(3):169-73. https://doi.org/10.1016/ 0922-338X(92)90078-9.

56. Tang $Y Q$, An MZ, Zhong YL, Shigeru M, Wu XL, Kida K. Continuous ethanol fermentation from non-sulfuric acid-washed molasses using traditional stirred tank reactors and the flocculating yeast strain KF-7. J Biosci Bioeng. 2010;109(1):41-6. https://doi.org/10.1016/j.jbiosc.2009.07.002.

57. Finlayson SD, Fleming C, Berry DR, Johnston JR. An improved lithiumacetate method for yeast transformation. Biotechnol Tech. 1991;5(1):13-8. https://doi.org/10.1007/BF00152747.

\section{Publisher's Note}

Springer Nature remains neutral with regard to jurisdictional claims in published maps and institutional affiliations.
Ready to submit your research? Choose BMC and benefit from:

- fast, convenient online submission

- thorough peer review by experienced researchers in your field

- rapid publication on acceptance

- support for research data, including large and complex data types

- gold Open Access which fosters wider collaboration and increased citations

- maximum visibility for your research: over $100 \mathrm{M}$ website views per year

At BMC, research is always in progress.

Learn more biomedcentral.com/submissions 